\title{
Impact of the Mean State on EI Niño-Induced Western North Pacific Anomalous Anticyclones during EI Niño Decaying Summer in AMIP Models
}

\author{
Xieyuan Wang, ${ }^{\mathrm{a}}$ Tim Li, ${ }^{\mathrm{b}, \mathrm{a}}$ AND ChaO HE ${ }^{\mathrm{c}}$ \\ ${ }^{\text {a }}$ Key Laboratory of Meteorological Disaster, Ministry of Education/Joint International Research Laboratory of Climate and \\ Environmental Change/Collaborative Innovation Center on Forecast and Evaluation of Meteorological Disasters, Nanjing \\ University of Information Science and Technology, Nanjing, China \\ ${ }^{\mathrm{b}}$ Department of Atmospheric Sciences, School of Ocean and Earth Science and Technology, University of Hawai' $i$ at Mānoa, \\ Honolulu, Hawaii \\ ${ }^{\mathrm{c}}$ Institute for Environmental and Climate Research, Jinan University, Guangzhou, China
}

(Manuscript received 25 September 2020, in final form 19 August 2021)

\begin{abstract}
Through the diagnosis of 29 Atmospheric Model Intercomparison Project (AMIP) experiments from the CMIP5, we investigate the impact of the mean state on simulated western North Pacific anomalous anticyclone (WNPAC) during El Niño decaying summer. The result indicates that the intermodel difference of the June-August mean precipitation in the Indo-western Pacific Ocean warm pool is responsible for the difference of the WNPAC. During the decaying summer of an eastern Pacific (EP)-type El Niño, a model that simulates excessive mean rainfall over the western North Pacific (WNP) reproduces a stronger WNPAC response, through an enhanced local convection-circulation-moisture feedback. The intensity of the simulated WNPAC during the decay summer of a central Pacific (CP)-type El Niño, on the other hand, depends on the mean precipitation over the tropical Indian Ocean. The distinctive WNPAC-mean precipitation relationships between the EP and CP El Niño result from different anomalous SST patterns in the WNP. Whereas the local SST anomaly plays an active role in maintaining the WNPAC during the EP El Niño, it plays a passive role during the CP El Niño. As a result, only the mean-state precipitation/moisture field in the tropical Indian Ocean modulates the circulation anomaly in the WNP in the latter case.
\end{abstract}

KEYWORDS: Atmosphere-ocean interaction; El Niño; General circulation models; Model errors

\section{Introduction}

The western North Pacific anomalous anticyclone (WNPAC) is the most pronounced low-level circulation system over the western North Pacific Ocean (WNP) that conveys El Niño impact to East Asia during its decaying summer (Zhang et al. 1996; Chang et al. 2000a,b; Wang et al. 2000, 2003; Wang and Zhang 2002; Li and Wang 2005; Li et al. 2017). It plays an important role in the El Niño-East Asian summer monsoon teleconnection (Wang et al. 2000; Chang et al. 2000a,b; Wu et al. 2003; Xie et al. 2016). The physical process through which the WNPAC influences the East Asian summer monsoon is through southerly anomalies on the west flank of the WNPAC that transport high moisture content from the tropical oceans to East Asia (Chang et al. 2000a; Li and Hsu 2017).

The WNPAC often develops in the fall of the El Niño developing year, reaches a maximum intensity during El Niño mature winter, and maintains its strength throughout the following spring and summer (Wang et al. 2000, 2003; Xie et al. 2009; Wu et al. 2009, 2010; Wu et al. 2017a,b). Many previous studies aimed to understand the mechanisms for the development and maintenance of the WNPAC. Wang et al. (2000, 2003) proposed a local wind-evaporation-SST feedback mechanism. In response to the El Niño heating in the equatorial central Pacific, a Rossby wave low-level cyclonic gyre appears to the west of the heat source. Northeasterly anomalies

Corresponding author: Tim Li, timli@hawaii.edu to the northwest flank of the cyclone anomaly enhance the mean northeasterly trade and surface evaporation, which cools the local SST. The surface cooling further induces an anomalous anticyclone to the west, as a Rossby wave response to the negative heating anomaly in situ. The setup of the WNPAC enhances the northeasterly anomaly to its east and promotes a positive wind-evaporation-SST-convection (WESC) feedback that maintains the cold SST anomaly (SSTA) and the WNPAC. This positive feedback process was further confirmed by a pacemaker coupled model experiment (Lau and Nath 2003). In addition to the local air-sea interaction process mentioned above, the atmospheric moist enthalpy advection process, through which cold and dry air is advected into the WNP by northerly anomalies to the western flank of the cyclonic anomaly induced by El Niño heating, also contributed to the establishment of the WNPAC during El Niño mature winter (Wu et al. 2017a,b).

The maintenance of the WNPAC throughout the El Niño decaying summer is through the following mechanisms: 1) local cold SSTA in the WNP (Wu et al. 2010), 2) the Indian Ocean (IO) capacitor effect (Xie et al. 2009; Wu et al. 2009), 3) central Pacific (CP) cold SSTA (Chen et al. 2012; Wang et al. 2013), and 4) the Atlantic capacitor effect (Li et al. 2017).

The mean northeasterly wind over the WNP changes to southwesterly from boreal winter and spring to summer due to the establishment of East Asian summer monsoon, and thus the WESC feedback changes from a positive to negative feedback (Xie et al. 2009; Wu et al. 2009). As a result, the local air-sea interaction mechanism proposed by Wang et al. (2000) 
does not operate during El Niño decaying summer. However, the local SSTA resulting from this mechanism is still significant in June and July and impacts the WNPAC, as demonstrated by Wu et al. (2010).

Accompanied by the El Niño, a basinwide warming appears in the tropical IO (TIO) from El Niño mature winter to the subsequent summer. It was shown that this IO SSTA forcing effect to the WNP circulation is season-dependent (Wu et al. 2009; Chen et al. 2016). It only becomes effective in El Niño decaying summer, through the following process: The positive heating over the TIO force a Kelvin wave response to the east, according to Gill (1980). As low-level easterly anomalies associated with the Kelvin wave response decreases with increased latitude, they generate an anticyclonic shear, which further induces boundary layer divergence in the WNP through the Ekman pumping effect. The divergence and associated descent motion reduce the moisture, leading to a negative heating and thus a low-level anticyclone in situ. (Yang et al. 2007; Li et al. 2008; Xie et al. 2009; Wu et al. 2009).

As a result of a rapid transition of ENSO phase, a cold SSTA appears in the central Pacific during the El Niño decaying summer. This cold SSTA shifts the rising limb of the Walker circulation westward, thus reducing convection around $160^{\circ} \mathrm{E}$ (Wang et al. 2013). The suppressed convection helps maintain the WNPAC by stimulating a Rossby wave response to its west, with a pair of anomalous anticyclonic gyres at low levels west of the anomalous heating (Gill 1980).

A warm SSTA appears over the tropical Atlantic during boreal spring because of remote midlatitude and tropical impacts of El Niño (Jiang and Li 2019). This Atlantic warm SSTA may exert a remote impact on the WNP circulation during El Niño decaying summer through a heating-induced eastward Kelvin wave response that may remotely affect the wind in the WNP with an Indian Ocean relaying effect (Yu et al. 2016; Zhang et al. 2017), or through a westward Rossby wave response that may modulate SSTA in the extratropical northeastern Pacific via an evaporation-wind-SST feedback (Ham et al. 2013).

All of the mechanisms above were proposed based on observational analyses and further validated by atmospheric or coupled general circulation models in previous studies (e.g., Lau and Nath 2003; Wu et al. 2010; Rong et al. 2010; Chen et al. 2012). Thus, these mechanisms should operate in climate models, given strong ENSO forcing signals. It is worth mentioning that while statistically significant results were found from these previous studies, it does not mean that all the proposed mechanisms should operate simultaneously.

To what extent do the current state-of-the-art global atmosphere general circulation models (GCMs) capture the WNPAC realistically? The diagnosis of CMIP3 and CMIP5 model outputs (Tao et al. 2015, 2018, 2019) indicated that the simulated WNPAC during the El Niño decaying summer was in general weaker and displaced northward relative to the observations. Tao et al. $(2018,2019)$ attributed the error to the ENSO-related SSTA bias and associated teleconnection processes. Given that the coupled models suffer from both the model mean state error and the bias associated with the ENSO related SSTA, it is necessary to separate their impact. This motivates the current study to diagnose the AMIP models with specified observed SSTA field. By doing that, we intend to focus on examining the effect of the mean state error in the ENSO-East Asia teleconnection.

The mean state modulation on the IO capacitor effect was demonstrated by Wu et al. (2010) in an atmospheric GCM (AGCM) simulation. They showed that the IO basin SSTA forcing effect is stronger in maintaining the WNPAC in late summer after the WNP monsoon trough is established. The result suggests that the SSTA is not the only factor that affects the WNPAC during the El Niño decaying summer, and the mean state also plays a role. It has been shown that many AGCMs suffer the severe discrepancies in capturing the observed rainfall patterns over the Indian and WNP monsoon regions (e.g., Lau et al. 1996; Kang et al. 2002; Annamalai et al. 2017).

The objective of the current study is to investigate the "pure" effect of the mean state on El Niño-induced WNPAC during its decaying summer through the diagnosis of 29 AMIP model simulations that are included in the CMIP5 model archive. All of these AMIP experiments were forced by prescribed historical SST and sea ice, so that one may focus on the contribution of the atmospheric mean state bias. Considering that the El Niño events can be classified into two types, eastern Pacific (EP) El Niño and central Pacific (CP) El Niño, on the basis of the location of the maximum SSTA center (Fu et al. 1986; Trenberth and Stepaniak 2001; Ashok et al. 2007; Kug et al. 2009) and that their global and regional impacts are different (e.g., Hu et al. 2012; Yu et al. 2012), we intend to analyze the simulated WNPAC among these AMIP models and the mean state bias dependence during the decaying summer of EP and $\mathrm{CP}$ El Niños respectively. It has been shown that the WNPAC associated with EP and CP events exhibits distinctive evolution features (Shi and Qian 2018).

The remaining part of this paper is organized as follows. The data and methods are introduced in section 2. The simulated WNPAC pattern in the multimodel ensemble average (MME) and its intermodel spread among 29 AMIP models are shown in section 3. The relationship between the simulated WNPAC and mean state biases and mechanisms behind the relationship are discussed in section 4 . Section 5 presents conclusions and discussion.

\section{Data and method}

Monthly data of the Atmospheric Model Intercomparison Project (AMIP) experiments from 29 models from phase 5 of the Coupled Model Intercomparison Project (CMIP5) models are used. These AMIP experiments were forced by the same prescribed SST and sea ice fields. The original horizontal resolution of the prescribed SST boundary conditions created by Program for Climate Model Diagnosis and Intercomparison (PCMDI) is $1^{\circ} \times 1^{\circ}$. The SST data are interpolated to each model's resolution for performing the AMIP experiments. A general description of the AMIP experiments is presented in Taylor et al. (2012). The current AMIP model analysis covers from 1979 to 2008 .

For comparison with observations, the observed and reanalysis datasets for the same period (from 1979 to 2008) are 
(a) DJF

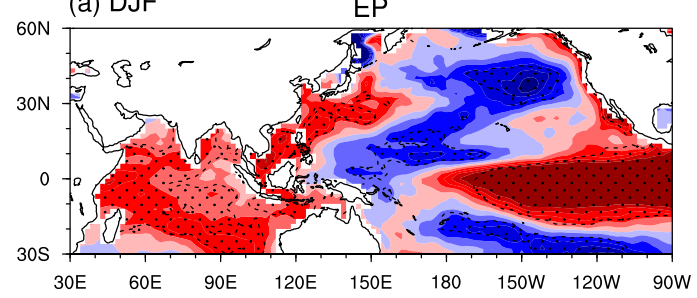

(b) JJA

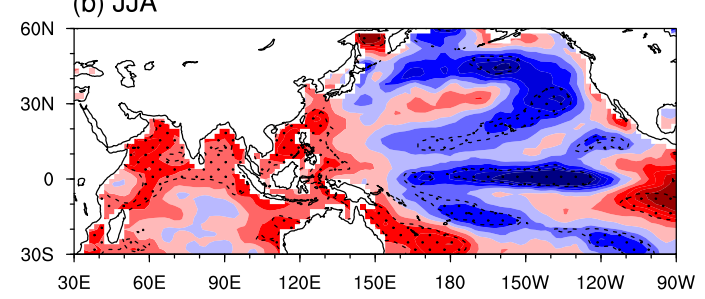

(c) DJF

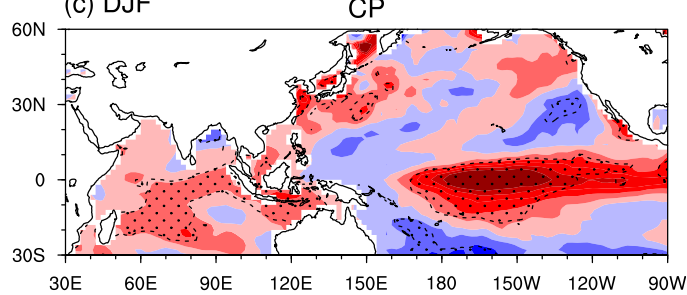

(d) JJA

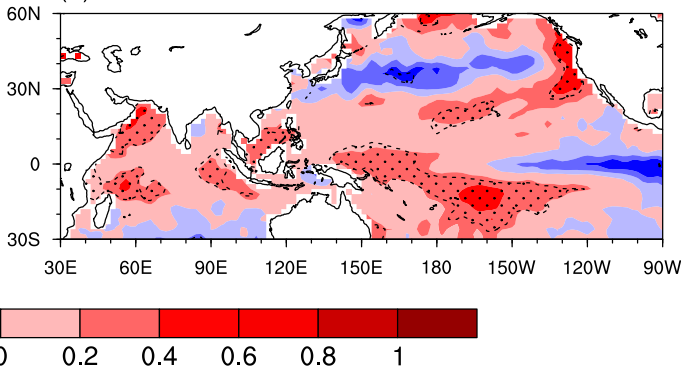

FIG. 1. Composite patterns of SST anomalies (shading; K) during El Niño (top) mature winter and (bottom) decaying summer for (a),(b) EP and (c),(d) CP El Niño. The stippled regions exceed the $95 \%$ confidence level based on Student's $t$ test.

used. Among them are the precipitation dataset from the Climate Prediction Center (CPC) Merged Analysis of Precipitation (CMAP; Xie and Arkin 1997) and three-dimensional wind and geopotential height fields from the European Centre for Medium-Range Weather Forecasts (ECMWF) interim reanalysis (ERA-Interim; Dee et al. 2011).
All the observational and model data above are interpolated onto $2^{\circ} \times 2^{\circ}$ grids. A least squares linear trend is applied to each field to remove the global warming trend. To measure quantitatively the WNPAC intensity, different variables such as zonal wind shear (e.g., Jiang et al. 2019), vorticity (e.g., He and Zhou 2014), and streamfunction were used in previous

\section{EP}

\section{(a) OBS}

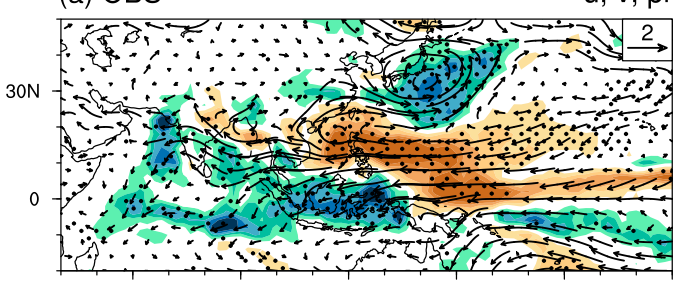

(b) MME

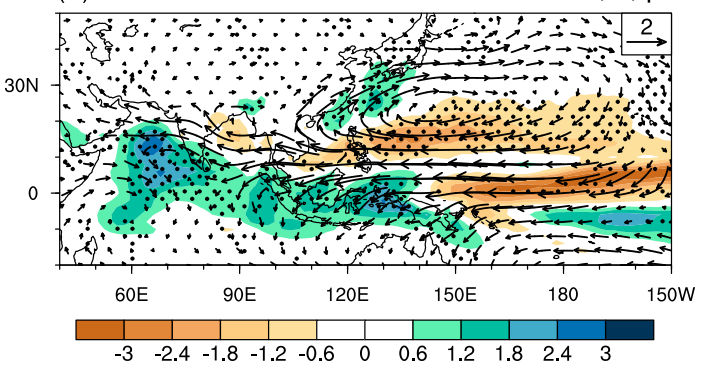

CP

(c) OBS u, v, pr

FIG. 2. Composite patterns of the (top) observed and (bottom) multimodel ensemble (MME) mean precipitation anomalies (shading; $\mathrm{mm} \mathrm{day}^{-1}$ ) and 850-hPa wind anomalies (vectors; $\mathrm{m} \mathrm{s}^{-1}$ ) during (a),(b) EP and (c),(d) CP El Niño decaying summer. The stippled regions indicate that the precipitation anomaly exceeds the $95 \%$ confidence level based on a two-tailed Student's $t$ test. The magnitude of the reference vector is 2 in (a) and (b) and 1 in (c) and (d). The interval of shading is 0.6 in (a) and (b) and 0.4 in (c) and (d). 
OBS

(a) EP

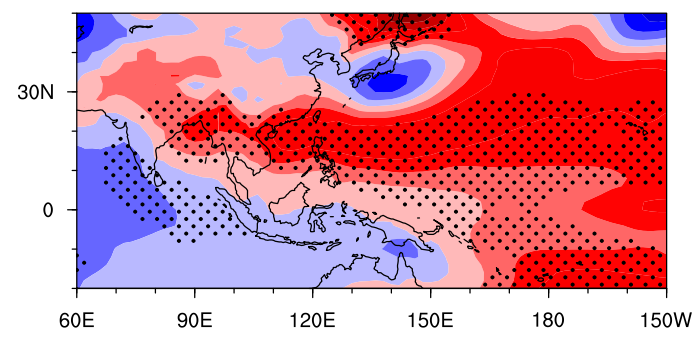

(b) $\mathrm{CP}$

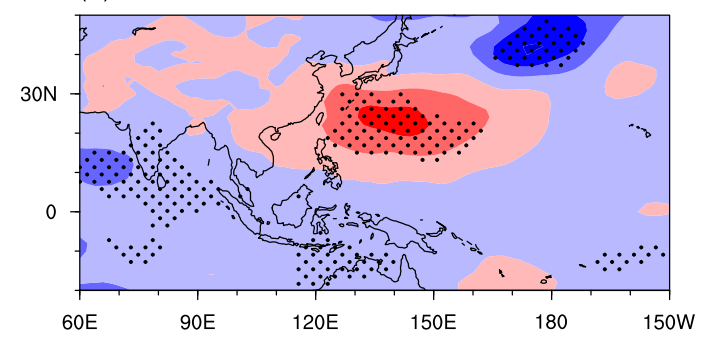

(c) EP-CP

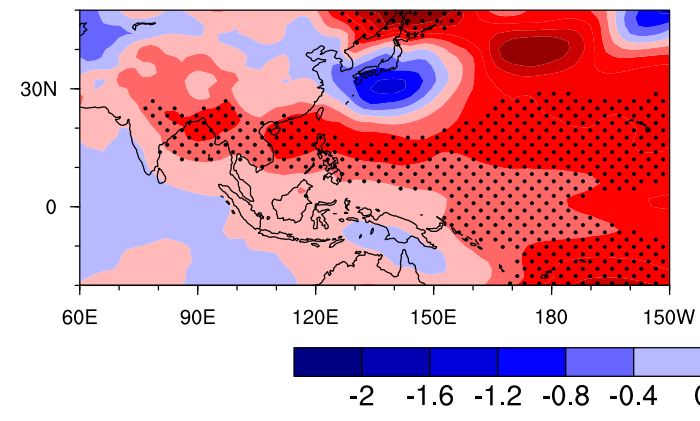

MME

(d) EP

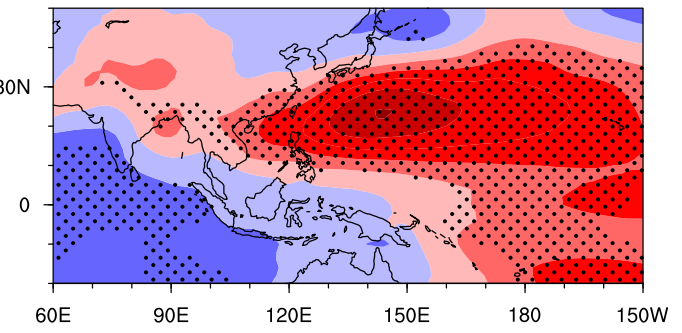

(e) $\mathrm{CP}$

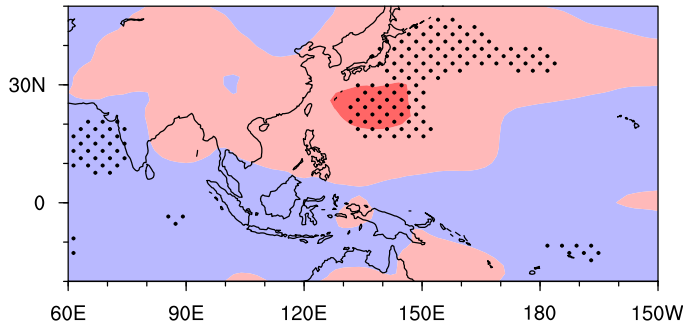

(f) EP-CP

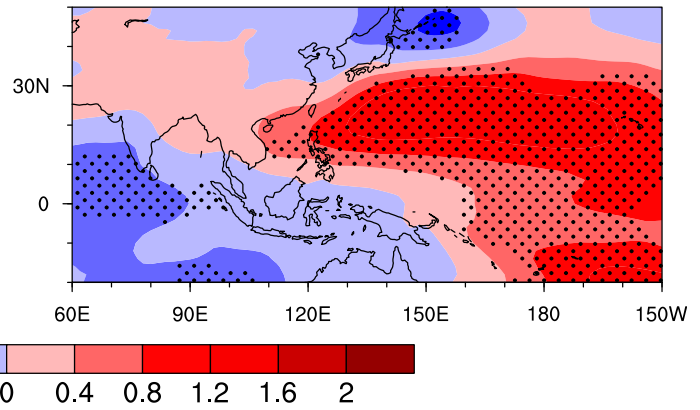

FIG. 3. Composite pattern of the (left) observed and (right) MME mean SLP anomaly during (a),(d) EP and (b),(e) CP El Niño decaying summer. Also shown is (c),(f) the difference between EP and CP cases. The stippled regions exceed the $95 \%$ confidence level based on a two-tailed Student's $t$ test.

studies. Here a WNPAC index is defined as the opposite sign of area-averaged anomalous relative vorticity at $850 \mathrm{hPa}$ over a key analysis domain over the WNP, following He and Zhou (2014). The domain was selected based on the maximum centers of anomalous relative vorticity and intermodel standard deviation of anomalous relative vorticity. It is $12^{\circ}-24^{\circ} \mathrm{N}, 110^{\circ}-$ $150^{\circ} \mathrm{E}$ for $\mathrm{EP} \mathrm{El} \mathrm{Niño}$ and $14^{\circ}-26^{\circ} \mathrm{N}, 110^{\circ}-150^{\circ} \mathrm{E}$ for $\mathrm{CP} \mathrm{El}$ Niño. Here the EP and CP El Niño events are identified using the location of the maximum SSTA center (i.e., whether the maximum SSTA center in the equatorial Pacific during El Niño mature winter is located to the west or east of $150^{\circ} \mathrm{W}$ ), following Zhang et al. (2013). According to this criterion, three EP El Niño cases $(1982 / 83,1987 / 88,1997 / 98)$ and five CP El Niño cases (1991/92, 1994/95, 2002/03, 2004/05, 2006/07) during 1979-2008 were identified. We focus on evaluating the model performance during El Niño decaying summer [June-August (JJA)].

A linear regression method is used to investigate the intermodel relationship between the WNPAC intensity and JJA mean precipitation. Each model is treated as a sample and the intermodel regression is done by regressing the JJA mean precipitation onto the WNPAC intensity index. The multimodel ensemble mean (MME) is calculated as an arithmetic average of variables among the 29 models. A random sampling method is used to distinguish if the differences between observation and MME arise from model bias or internal atmospheric variability, following Deser et al. (2017).

\section{Observed and simulated WNPAC during two types of El Niño}

The observed SSTA patterns during El Niño mature winter (DJF) and decaying summer (JJA) for two types of El Niño are shown in Fig. 1. In the mature winter, the maximum SSTA center in CP El Niño shifts to the west, relative to EP El Niño. A stronger negative SSTA in the western North Pacific and a stronger positive SSTA off the coast of East Asia and in the tropical Indian Ocean occur in the EP El Niño composite than 
EP

(a) OBS EP

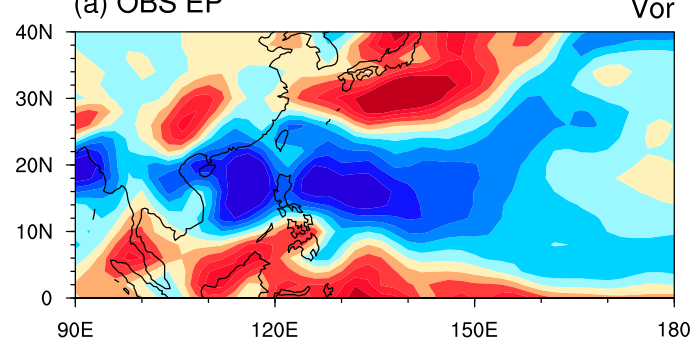

(b) MME EP

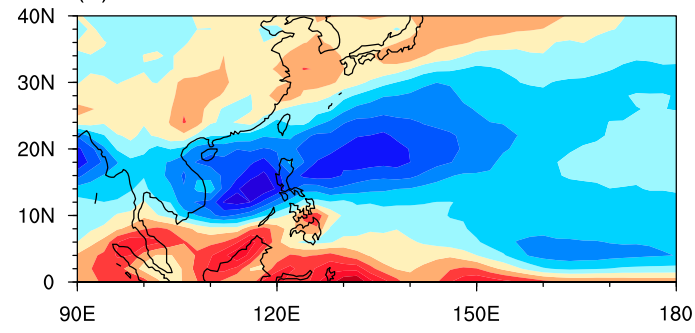

(c) OBS-MME

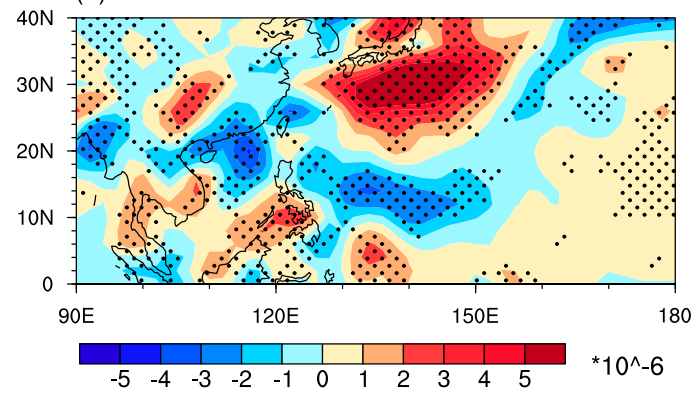

CP

(d) OBS CP

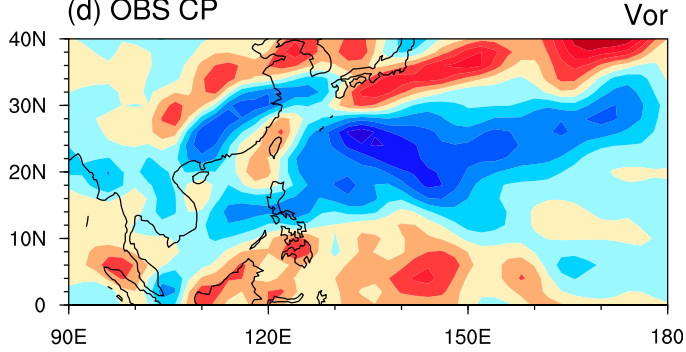

(e) MME CP

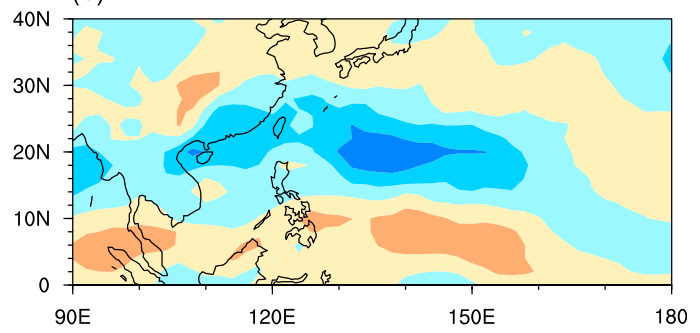

(f) OBS-MME

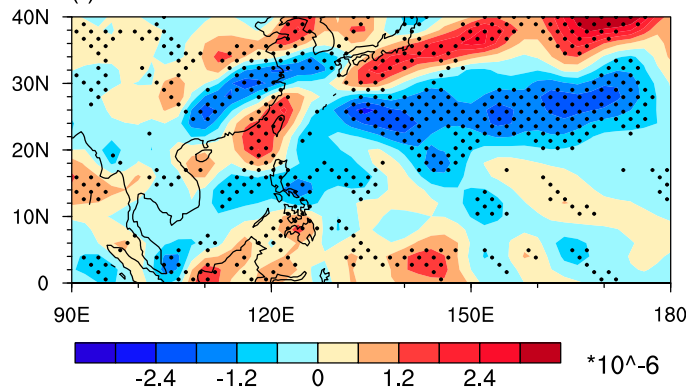

FIG. 4. Composite patterns of the relative vorticity anomalies on $850 \mathrm{hPa}$ for (top) observations and (middle) the MME mean, and (bottom) their difference, during (left) EP and (right) CP El Niño decaying summer. The stippled regions indicate that the observed composite has values lower than the 1st percentile or greater than the 99th percentile of 2000 bootstrapped model samples.

in the CP El Niño composite (Figs. 1a,c). In the decaying summer, the cold SSTA in the western Pacific is still present during EP El Niño composite, whereas the local cold SSTA during the CP El Niño composite dissipates (Figs. 1b,d). This implies a much stronger local SSTA forcing in the WNP during EP El Niño decaying summer. Another noted difference is the sign of the SSTA in the equatorial central Pacific. A negative SSTA occurs in the region during EP El Niño, and a positive SSTA occurs in the region during CP El Niño. This difference implies a distinctive CP SSTA forcing effect between EP and CP El Niño, as proposed by Wang et al. (2013).

The distinctive SSTA patterns between EP and CP El Niño composites suggest that different mechanisms may operate to maintain the WNPAC for EP and CP El Niño. This explains why one needs to examine the WNPAC processes separately.

The left panels of Fig. 2 show the horizontal patterns of observed and simulated MME precipitation and $850-\mathrm{hPa}$ wind anomalies during EP El Niño decaying summer. The WNPAC is seen clearly in the observations, which is located between $10^{\circ}$ and $30^{\circ} \mathrm{N}$. There is a negative precipitation anomaly in the southeast quadrant of the WNPAC, and the WNPAC can be considered as a Rossby wave-like response to the negative precipitation anomalies over the tropical WNP (Gill 1980; Wu et al. 2017a). There is also an anomalous cyclone with positive precipitation anomaly on the north of the WNPAC, resembling a Pacific-Japan teleconnection pattern (Nitta 1987). The Maritime Continent and the northern Indian Ocean are covered by positive precipitation anomaly. The observed WNPAC during EP El Niño decaying summer is reproduced by the MME (Fig. 2b). The major difference is that the simulated WNPAC and the associated negative precipitation anomaly are weaker than the observation. And the negative precipitation anomaly also shifts southeast relative to observation.

The right panels of Fig. 2 illustrate the CP El Niño counterpart. As seen in the observation (Fig. 2c), the WNPAC also appears over the WNP during the decaying summer of $\mathrm{CP} \mathrm{El}$ Niño. A negative precipitation anomaly is seen over the WNP, whereas a positive precipitation anomaly is observed over the 
EP

(a) CI OBS

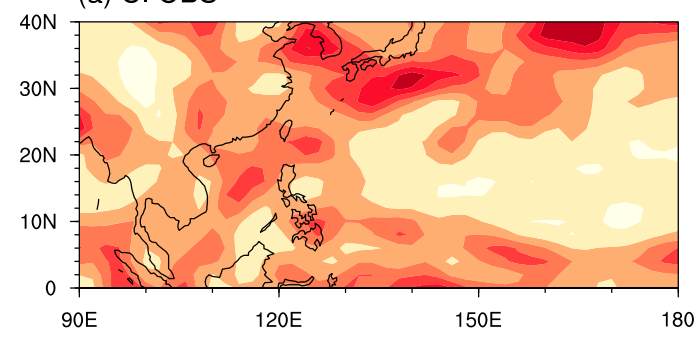

(b) CI MME

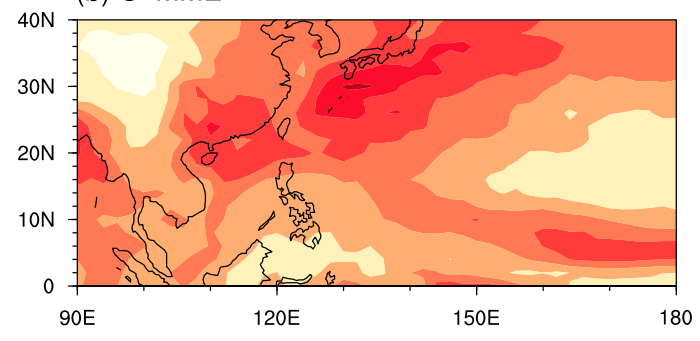

(d) $\mathrm{Cl}$ OBS

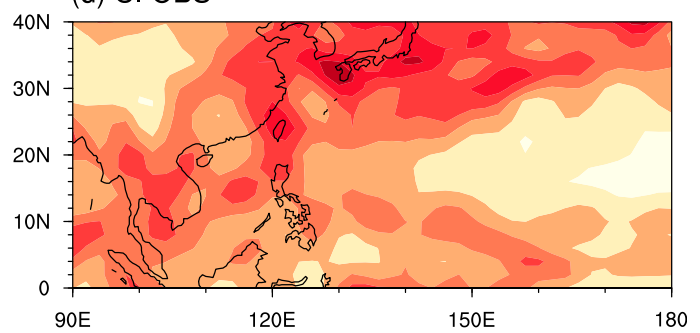

(e) CI MME

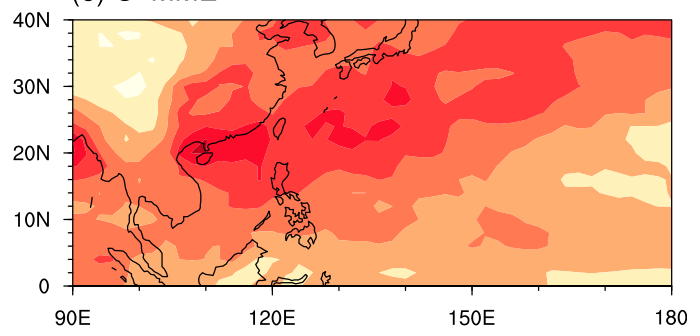

(c) OBS-MME

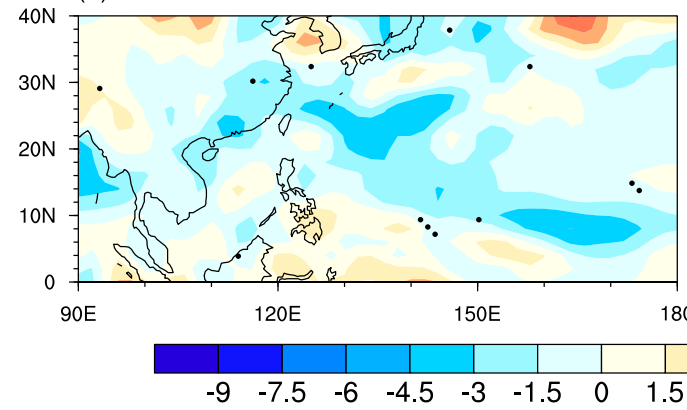

(f) OBS-MME

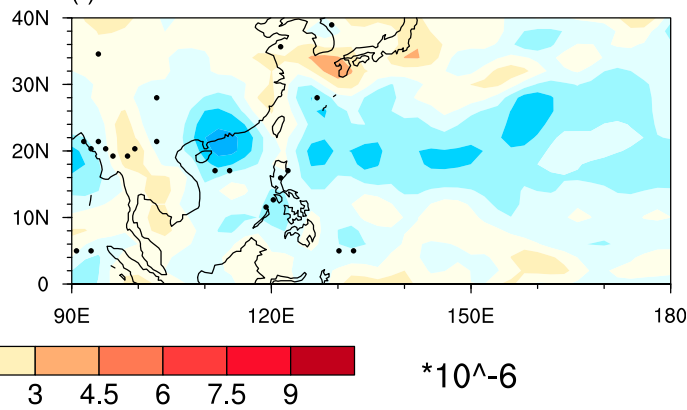

FIG. 5. The $1 \%-99 \%$ CIs on the 850 -hPa relative vorticity composites for (top) observations and (middle) the MME mean, and (bottom) their difference, in (left) EP and (right) CP events. The stippled regions indicate that the observed CI has values greater than the maximum CI or less than the minimum CI of any of the 29 models.

TIO, which may be responsible for maintaining the WNPAC (Wu et al. 2009; Xie et al. 2009). The main characteristics of the WNPAC during CP El Niño decaying summer are reproduced by the MME, even though the simulated WNPAC and associated negative precipitation anomalies are weaker than the observed (Fig. 2d). Note that the wind arrow size in the CP composite is only a half of that used in the EP composite. This indicates that the WNPAC associated with the CP events is in general weaker than that in the EP events. Such a difference appears in both the observation and MME. However, even though the CP WNPAC is weaker than the EP counterpart, it is statistically significant, exceeding the $95 \%$ significance level.

Figure 3 illustrates the composite sea level pressure (SLP) patterns for the observations and MME. The SLP field is consistent with the $850-\mathrm{hPa}$ wind field; that is, the WNPAC signals during both the CP and EP El Niño events are statistically significant while the former is weaker than the latter. It appears that the center of the WNPAC during the EP El Niño shifts slightly to the south and extends farther westward, relative to the CP El Niño. However, the MME cannot reproduce the meridional shift. A possible cause is that the models tend to simulate a much weaker rainfall anomaly near Japan in the EP events so that an anomalous cyclone north of the WNPAC is missing.

Previous studies proposed that the differences between the observations and MME could arise from internal atmospheric variability (Deser et al. 2017). It is difficult to address this issue based on limited El Niño samples. We follow the method proposed by Deser et al. (2017). There are 29 models, and each model has three EP and five CP events. The anomalies from climatology for each individual event in each model are calculated in advance. Then we put all these $87 \mathrm{EP}$ and $145 \mathrm{CP}$ events into two groups and form bootstrapped EP and CP composites by randomly sampling with replacement from these EP and CP events respectively. We always extract 87 samples for EP events and 145 samples for CP events (individual events can occur multiple times) and get 2000 bootstrapped composites. The composite patterns of the relative 
EP

(a) OBS

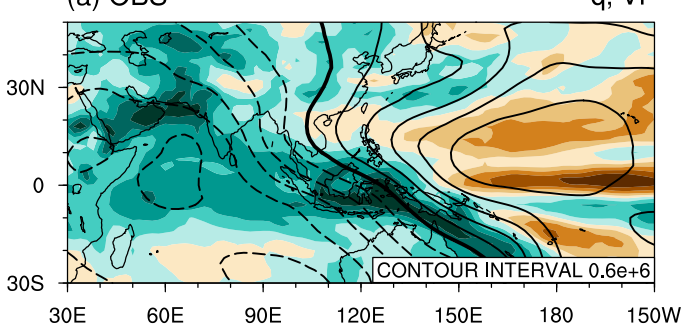

q, VP

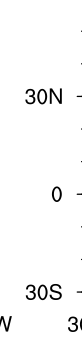

\section{CP}

(c) OBS

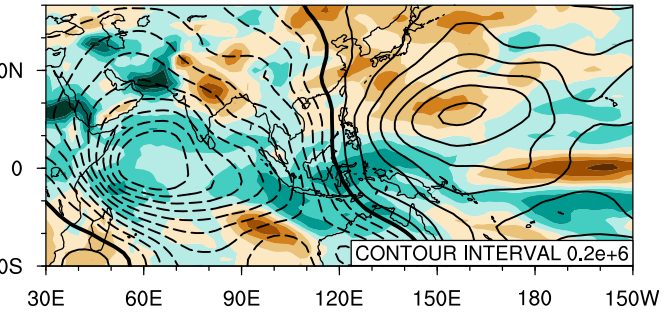

(b) MME

q, VP

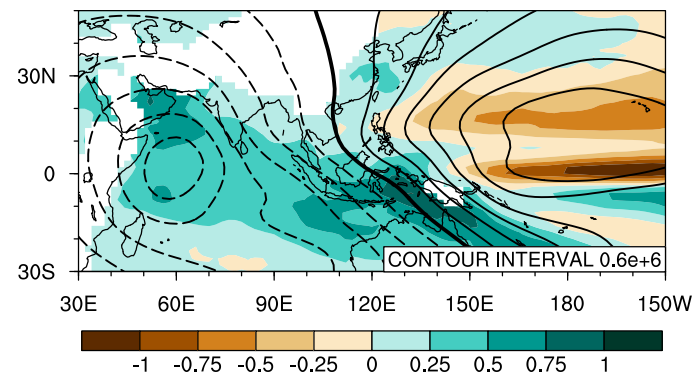

(d) MME

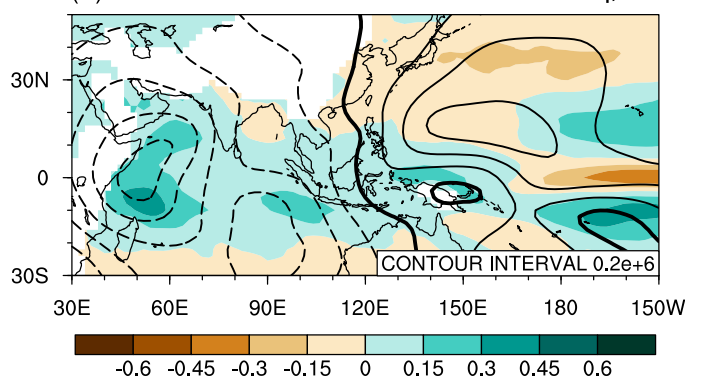

FIG. 6. Composite patterns of the (top) observed and (bottom) MME mean low-level (925-700-hPa average) specific humidity anomalies (shading; $\mathrm{g} \mathrm{kg}^{-1}$ ) and $200-\mathrm{hPa}$ velocity potential anomalies (contours; the thick line is zero) during (a),(b) EP and (c),(d) CP El Niño decaying summer. The contour interval is $0.6 \times 10^{6}$ in (a) and (b) and $0.2 \times 10^{6}$ in (c) and (d). The interval of shading is 0.25 in (a) and (b) and 0.15 in (c) and (d).

vorticity anomalies at $850 \mathrm{hPa}$ from observations and from MME, and their difference, are shown in Fig. 4. The dotted areas in Figs. 4c and 4f indicate regions where the observed composite vorticity anomalies are lower than the 1st percentile or greater than the 99 th percentile of the 2000 bootstrapped composites. In EP events, it is virtually certain that the negative values from the South China Sea to the east of the Philippines and the positive values in the northern part of the WNP are model biases. This indicates that the WNPAC reproduced by MME is weaker than observed. It shifts to the north possibly due to underestimate of the anomalous cyclone near Japan. In CP events, the WNPAC in the MME is also weaker than that in the observation, which is attributed to the model biases.

However, the model biases may be incorrectly determined with this method if the model's variability is unrealistic. Thus, we also calculate the confidence intervals (CIs) for models and observations (Fig. 5) to assess whether the model's variability is realistic, following Deser et al. (2017). The CIs are defined by the difference between the 99th and 1st percentiles of the 2000 bootstrapped composites at each grid point. The CI for each individual model is obtained by randomly sampling three EP and five CP events from the corresponding model, calculating composite mean and then identifying the 1st percentile and 99th percentile. The observed CI is obtained in the same way. The stippled areas in Figs. $5 \mathrm{c}$ and $5 \mathrm{f}$ indicate regions where the observed CI greater than the maximum CI or less than the minimum CI of any of the 29 models. There are only few stipples in Figs. 5c and 5f. So, the models' CIs encompass the observed CI in most of the area over the WNP, although it is slightly larger than observed CI. Thus, the internal variabilities in the models correspond well to observations in general. This further confirms that the differences discussed above mainly arise from model biases instead of internal variability.

The low-level specific humidity (averaged from 925 to $700 \mathrm{hPa}$ ) and upper-level velocity potential anomaly fields (Fig. 6) show a consistent feature with the precipitation and circulation anomaly fields (Fig. 2). During EP El Niño decaying summer, a negative moisture anomaly occurs over the suppressed convection region in the WNP, whereas a positive moisture anomaly is seen from the northern Indian Ocean to the Maritime Continent. The moisture pattern in CP El Niño composite is in general similar to that of EP El Niño composite, with a noticeable difference over the WNP: the negative moisture anomaly is located to the west and covers less area when compared with EP cases. The 200 -hPa velocity potential anomaly fields show a west-east dipole pattern, suggesting anomalous ascending motion over the TIO and anomalous descent over the WNP in both EP and CP El Niño composites, although the descending center in CP cases is weaker and shifts to the west. The MME tends to underestimate the strength of both the moisture and velocity potential anomalies.

It is worth mentioning that, when compared with the weaker and less organized precipitation pattern over the TIO associated with the CP events (Fig. 2d), the $200-\mathrm{hPa}$ velocity potential and moisture anomaly fields show a more consistent large-scale feature over the TIO (Figs. 6c,d). This implies that the MME is able to capture the basin-scale anomalous vertical motion and heating fields over the TIO. 
(a) EP

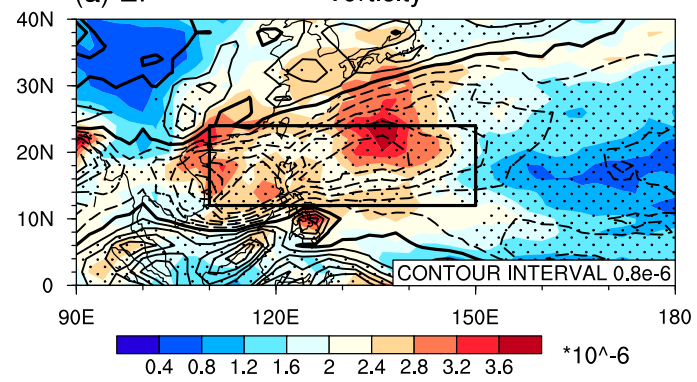

(c) EP

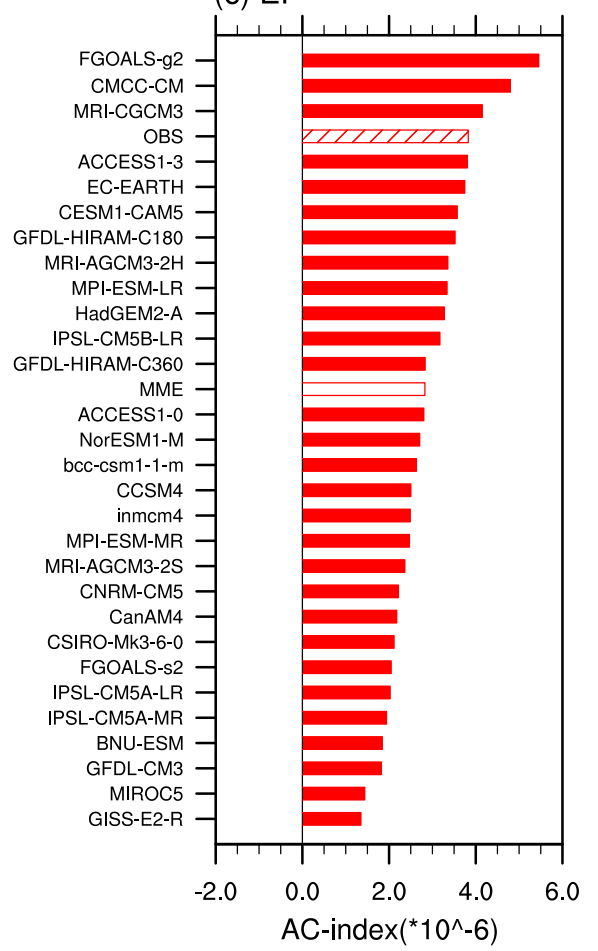

(b) $\mathrm{CP}$

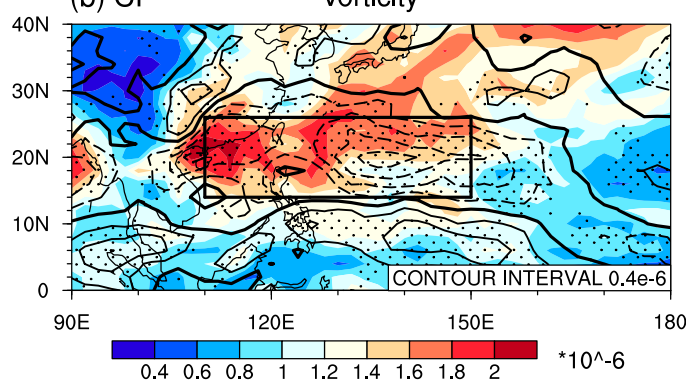

(d) $\mathrm{CP}$

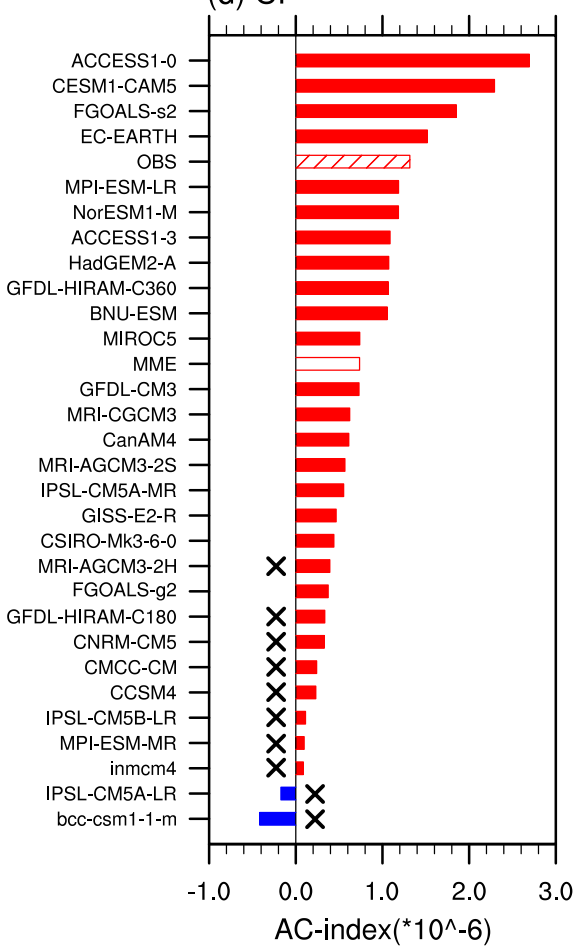

FIG. 7. The MME (contours) and intermodel standard deviation (shading) of 850-hPa relative vorticity anomalies $\left(\mathrm{s}^{-1}\right)$ during (a) EP and (b) CP El Niño decaying summer. Regions in which $70 \%$ of the models have the same sign of relative vorticity anomalies are stippled. The black-outlined box is used to define the WNPAC intensity index. The intervals of the contours and shading are $0.8 \times 10^{-6}$ and $0.4 \times 10^{-6}$, respectively, in (a) and $0.4 \times 10^{-6}$ and $0.2 \times$ $10^{-6}$, respectively, in (b). Also shown is the WNPAC intensity index derived from individual models for (c) EP and (d) CP El Niño. The open bars represent the MME, and the hatched bars represent the observational counterpart. The models that cannot pass the $95 \%$ significant test are marked with $\mathrm{x}$.

To quantitatively measure the models' performance in capturing the WNPAC strength, a WNPAC intensity index is introduced. It is defined as the opposite sign of an areaaveraged $850-\mathrm{hPa}$ relative vorticity anomaly so that a larger index represents a stronger WNPAC. The domain selection is based on the horizontal distributions of the MME of the simulated $850-\mathrm{hPa}$ relative vorticity field and its intermodel standard deviation (Figs. 7a,b). Note that the maximum of intermodel difference appears near the center of the simulated WNPAC in both EP and CP El Niño composites. It suggests that there is a pronounced difference in the intensity of the simulated WNPAC among 29 AMIP models, while the difference in the WNPAC location is relatively small. The black boxes in Figs. $7 \mathrm{a}$ and $7 \mathrm{~b}$ cover the center of the simulated WNPAC and are chosen as the key analysis domain for EP and CP El Niño. The domain covers $12^{\circ}-24^{\circ} \mathrm{N}, 110^{\circ}-150^{\circ} \mathrm{E}$ for EP El Niño and $14^{\circ}-26^{\circ} \mathrm{N}, 110^{\circ}-150^{\circ} \mathrm{E}$ for $\mathrm{CP} \mathrm{El}$ Niño.

The so-calculated WNPAC intensity indices for the observation, the MME, and individual models are shown in Figs. 7c and $7 \mathrm{~d}$. Most of the AMIP models are able to reproduce the correct sign of the WNPAC in both EP and CP El Niños, even though their amplitudes differ greatly. The MME of the WNPAC intensity is weaker than the observed in both EP and CP El Niño cases. All of the indices for EP events and 19 of 29 
models' indices for CP events exceed the $95 \%$ confidence level, and so do the observation and MME. The difference between EP and CP WNPAC indices among the 29 models is also tested, and it exceeds the $99 \%$ confidence level. This validates that the WNPAC in CP events is significantly weaker than that in EP events.

\section{Relationships between the mean precipitation and the WNPAC intensity and associated mechanisms}

Given the same SSTA forcing, the different WNPAC responses in the models may result from the mean precipitation bias. The internal atmospheric variability could also contribute to intermodel difference, and it is hard to distinguish model bias and internal variability with only one member for each model. This issue will be addressed below. Before examining the mean state impact, we first examine the anomalous precipitation and circulation distributions associated with a strong WNPAC index. An intermodel regression among the 29 models is done by regressing the precipitation anomalies and 850-hPa wind anomalies fields onto the standardized WNPAC indices for EP and CP El Niño respectively (Fig. 8). A high WNPAC index is associated with an anomalous anticyclone and a negative precipitation anomaly over the WNP in both EP and CP El Niño, except that they shift slightly to the west in the CP El Niño. It indicates that the models with a greater WNPAC index simulate a stronger negative precipitation anomaly over the WNP. This is physically understandable, since the WNPAC can be viewed as a Rossby wave response to a negative precipitation over the WNP (Gill 1980; Wu et al. 2017a). A stronger negative precipitation anomaly induces a stronger WNPAC. The enhanced easterly anomalies to the southeast flank of WNPAC could further intensify the negative precipitation anomaly through dry advection (Wu et al. 2017a).

As seen in Fig. 8b, a positive precipitation anomaly appears from the TIO to the Maritime Continent, along with anomalous easterlies from the WNP to the northern IO. This suggests that a stronger basinwide positive heating anomaly over the TIO may be responsible for inducing a stronger WNPAC during CP El Niño decaying summer. This IO heating effect was proposed by various previous studies (e.g., Wu et al. 2009; Xie et al. 2009). The TIO heating can affect the circulation over the WNP through a Kelvin wave response. An anticyclonic shear associated with the Kelvin wave easterly anomalies may weaken the WNP monsoon and induce negative precipitation through Ekman pumping induced boundary layer divergences, and the weakened monsoon heating may further induce a lowlevel anticyclone (Wu et al. 2009). Therefore, a stronger positive precipitation anomaly in the TIO during CP El Niño may induce a stronger WNPAC through a greater Kelvin wave response. In contrast, no clear precipitation anomaly signal appears over the equatorial IO during EP El Niño (Fig. 8a). The negative precipitation also appears over the WNP, similar to EP events. Of course, the local negative heating can also have a positive feedback with the WNPAC in CP events. However, it must be caused by the anticyclonic shear associated with the IO forcing instead of local SSTA, because a warm SSTA appears in the WNP in JJA (Fig. 1d).

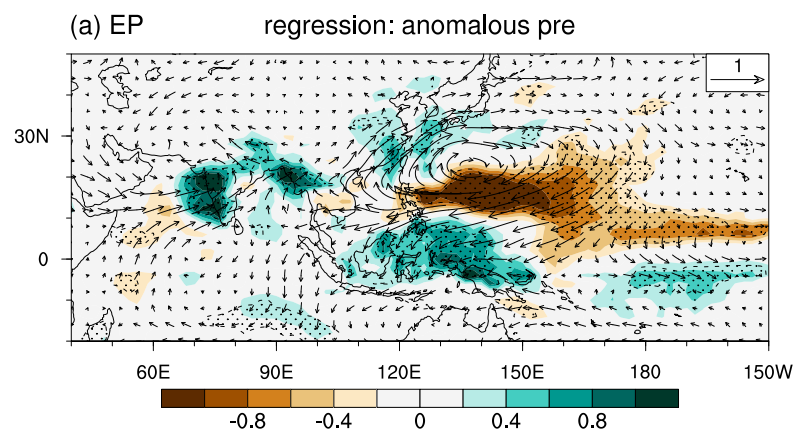

(b) $\mathrm{CP}$

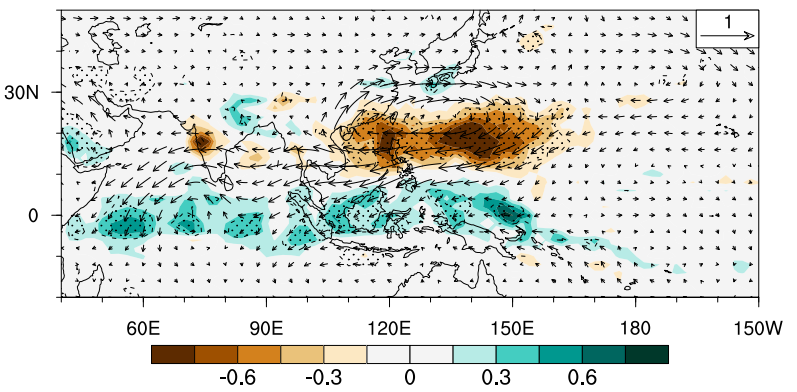

FIG. 8. The precipitation anomalies (shading; $\mathrm{mm} \mathrm{day}^{-1}$ ) and 850-hPa wind anomalies (vectors; $\mathrm{m} \mathrm{s}^{-1}$ ) regressed onto the standardized WNPAC indices during (a) EP and (b) CP El Niño decaying summer. The stippled regions indicate that the regressed precipitation anomalies exceed the $95 \%$ confidence level.

Next, we examine the relationship between the mean precipitation and the WNPAC intensity index among the 29 models. Figures $9 \mathrm{a}$ and $9 \mathrm{~b}$ show the summer mean (JJA) precipitation and $850-\mathrm{hPa}$ wind fields regressed onto the standardized WNPAC index for EP and CP El Niño. As seen in Fig. 9a, a model with a higher WNPAC index during EP El Niño decaying summer simulates higher mean precipitation over the WNP and the Indochina Peninsula but less mean precipitation over the Maritime Continent and the equatorial IO. Such a model also simulates a stronger mean westerly at low level over the northern IO and WNP and a stronger northward cross-equatorial flow over the Indian Ocean and the Maritime Continent.

The relationship between the mean precipitation and the WNPAC intensity can be further confirmed by a scatter diagram between the mean precipitation averaged over the red box in Fig. 9a and the WNPAC index. As seen in Fig. 9c, the WNPAC index and the JJA mean precipitation in the WNP are significantly correlated. The correlation coefficient is 0.69 , exceeding the $99 \%$ confidence level.

In contrast to EP El Niño, the most significant mean precipitation signal that correlates to the WNPAC index for CP El Niño appears over the equatorial IO (i.e., the red box in Fig. 9b). The regressed mean precipitation over the WNP is much weaker and statistically insignificant. The result suggests that the intermodel difference of the simulated WNPAC during the CP El Niño is primarily determined by the IO capacitor effect that is modulated by the mean precipitation in situ. 
(a) EP

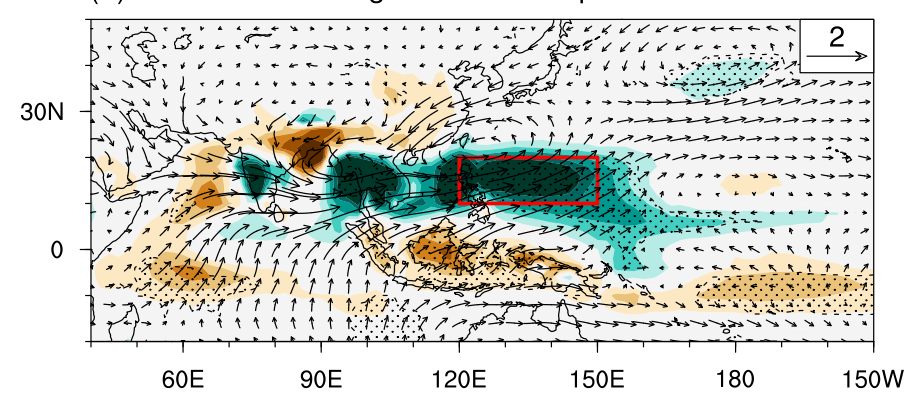

(b) $\mathrm{CP}$

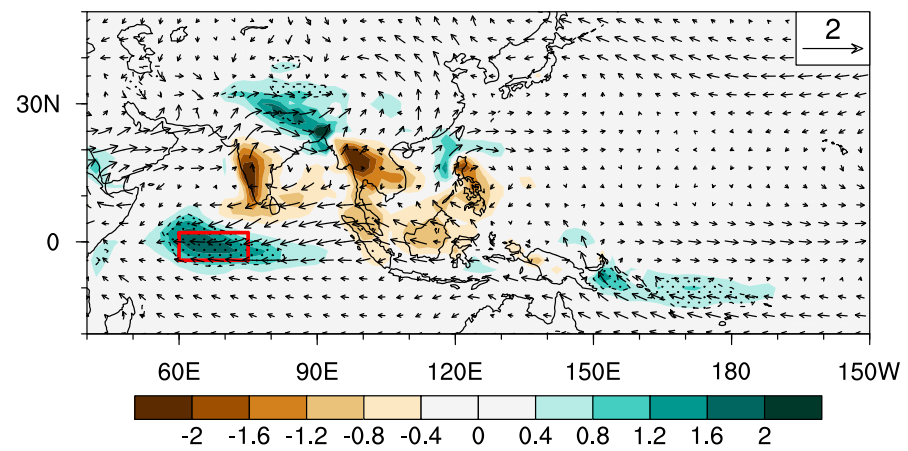

(c) EP

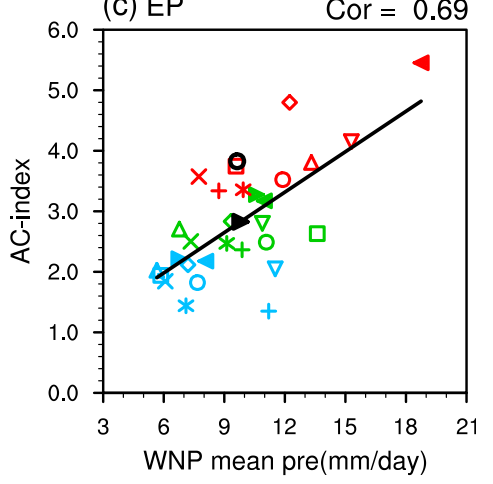

(d) $\mathrm{CP}$

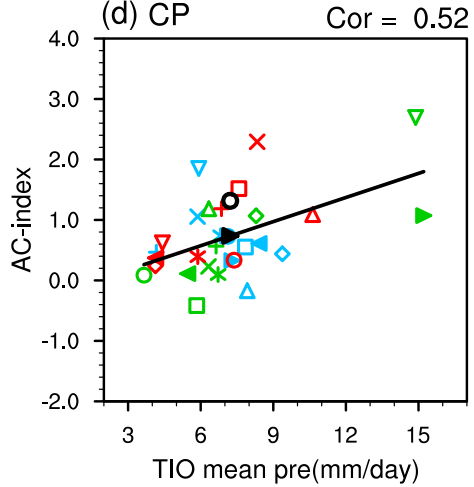

O GFDL-HIRAM-C180

$\diamond$ GFDL-HIRAM-C360

+ GISS-E2-R

> HadGEM2-A

O inmcm4

$\triangle$ IPSL-CM5A-LR

IPSL-CM5A-MR

IPSL-CM5B-LR

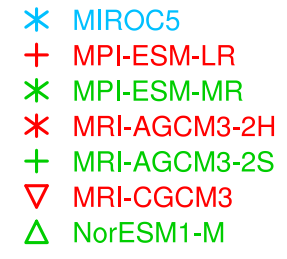

$\triangle$ NorESM1-M

FIG. 9. The JJA mean precipitation (shading; $\mathrm{mm} \mathrm{day}^{-1}$ ) and $850-\mathrm{hPa}$ wind (vector; $\mathrm{m} \mathrm{s}^{-1}$ ) fields regressed onto the standardized WNPAC indices for (a) EP and (b) CP El Niño. Stippled regions indicate that the regressed mean precipitation exceeds the $95 \%$ confidence level. Also shown are scatter diagrams between the averaged [inside the red-outlined box in (a) and (b)] mean precipitation and the WNPAC index for (c) EP and (d) CP El Niño. For the EP El Niño in (c), JJA mean precipitation over the WNP [red-outlined box in (a)] was used against the WNPAC index. For the CP El Niño in (d), JJA mean precipitation over the TIO [red-outlined box in (b)] was used. The correlation coefficients for both (c) and (d) exceed the $99 \%$ confidence level.

Figure 9d displays a scatter diagram between the mean precipitation averaged over the red box in Fig. $9 \mathrm{~b}$ and the WNPAC index. The correlation coefficient between them is 0.52 , which is significant at the $99 \%$ confidence level.

To compare the magnitude of spread due to internal variability versus that due to model physics, 5 models among the 29 AMIP models that have 5-10 members (CSIRO Mk3.6.0, GFDL CM3, HadGEM2-A, IPSL-CM5A-LR, and MRICGCM3) are further analyzed. In Fig. 10, each member of these selected models is treated as an individual sample and calculation method is exactly the same as Figs. 9c and 9d. It is clear in Fig. 10a that the internal variability in both the WNPAC-index and precipitation are smaller than intermodel variability. In Fig. 10b, while the internal variability is smaller than intermodel variability in precipitation, they are comparable in the WNPAC-index. The standard deviation is used to estimate their magnitudes. It turns out that the intermodel standard deviation of the WNPAC index is 0.97 for EP events and 0.70 for CP events. The standard deviations of the WNPAC index within individual models range from 0.16 to 0.25 for EP events and from 0.15 to 0.26 for CP events. The result validates that the internal variability is smaller than the intermodel variability, even though their difference is smaller in $\mathrm{CP}$ than EP events. This implies that the intermodel difference is critical.

The distinctive mean state dependences between the EP and CP El Niño imply that different mechanisms may operate to maintain the WNPAC throughout the decaying summer. To illustrate this point, we plotted the mean specific humidity fields regressed onto the standardized WNPAC index for EP 
(a) EP (selected models)

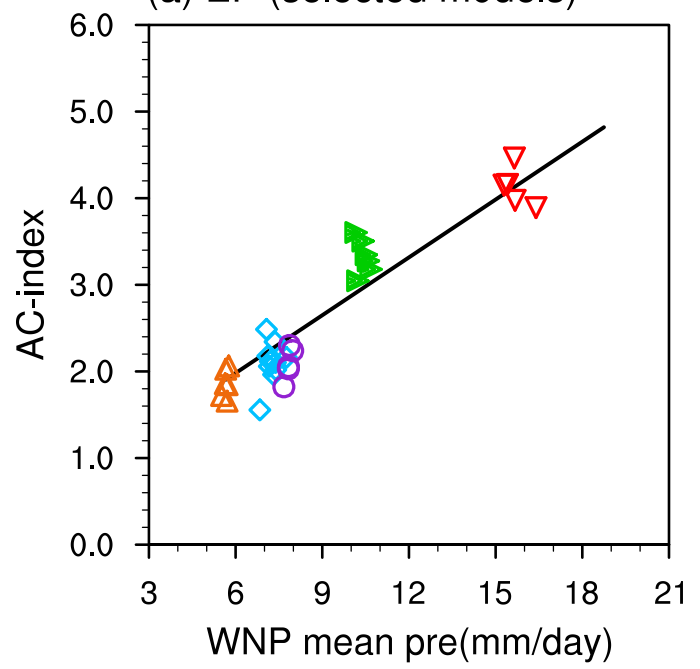

(b) CP (selected models)

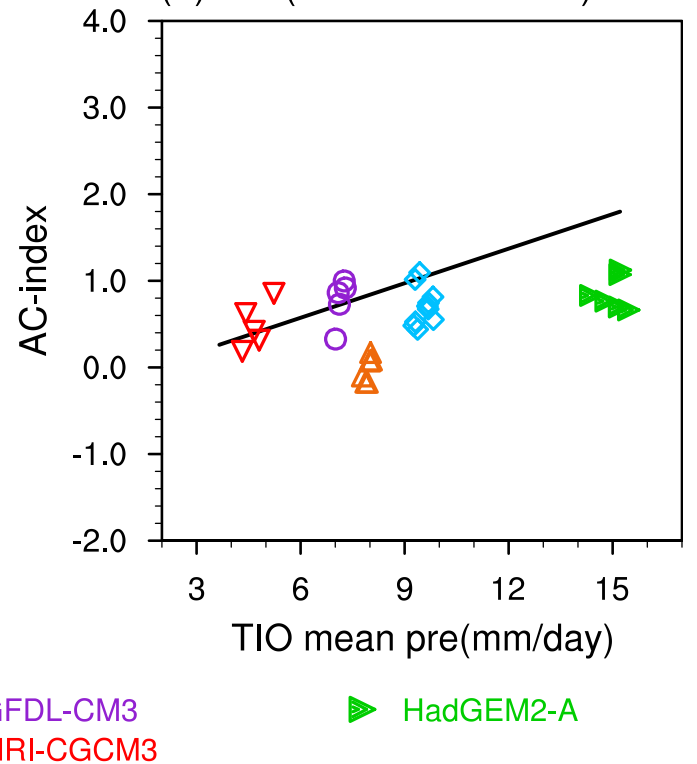

FIG. 10. As in Figs. 9c and 9d, but for multiple members of five selected models represented by the different symbols. The black lines are the regression lines shown in Figs. 9c and 9d.

and CP El Niño in Fig. 11. A significantly higher background mean moisture in lower troposphere appears in the WNP during EP El Niño (Fig. 11a), whereas no significant mean moisture signal is found in the same region during CP El Niño (Fig. 11b). In contrast, a significantly higher mean moisture appears in the equatorial IO during CP El Niño, whereas no or even lower mean moisture signal appears in the same region during EP El Niño.

Physically, it is argued that a higher background mean moisture promotes a greater positive feedback between the anomalous circulation and convection. This is because even given the same perturbation wind initially, a greater background mean moisture would lead to a greater perturbation condensational heating, which could strengthen the perturbation circulation through the enhanced heating. Following the argument above, one would expect a greater perturbation circulation-convection feedback over the WNP (IO) during EP (CP) El Niño decaying summer.

Why is a greater background mean precipitation often associated with a greater background mean moisture state? A greater mean precipitation implies a greater mean upward motion. Because the mean moisture decreases exponentially with height, a mean ascending motion transports more moisture upward, leading to a greater increase of the mean moisture in situ. While part of the increased moisture condensates as precipitation, the remaining part is used to moisten the atmosphere. The maximum moisture increase happens in the lower troposphere because of greatest moisture gradient there.

A method was developed to measure the strength of the perturbation circulation-convection feedback for each model. Figure 12a shows the MME of the precipitation and low-level averaged (1000-850 $\mathrm{hPa}$ ) relative vorticity anomaly during El Niño decaying summer. It indicates that the maximum centers of the negative vorticity and precipitation anomalies in the WNP are approximately in phase. Thus, one may calculate a regression coefficient between area-averaged precipitation and vorticity anomalies for each summer of 1979-2008 over the WNP domain $\left(12^{\circ}-22^{\circ} \mathrm{N}, 130^{\circ}-166^{\circ} \mathrm{E}\right.$; the red-outlined box in Fig. 12a). A greater regression coefficient implies a model with a stronger positive feedback on the interannual time scale.

(a) EP regression: mean q

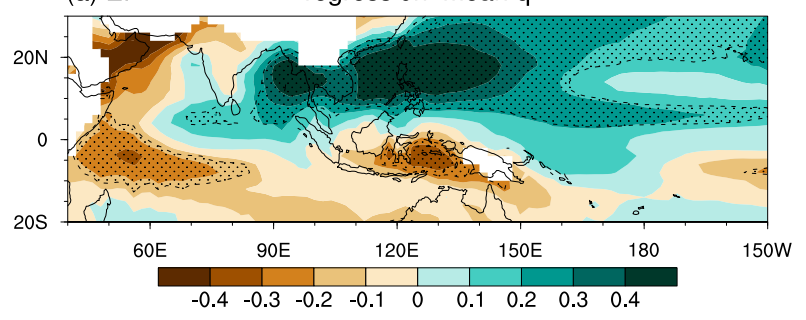

(b) $\mathrm{CP}$

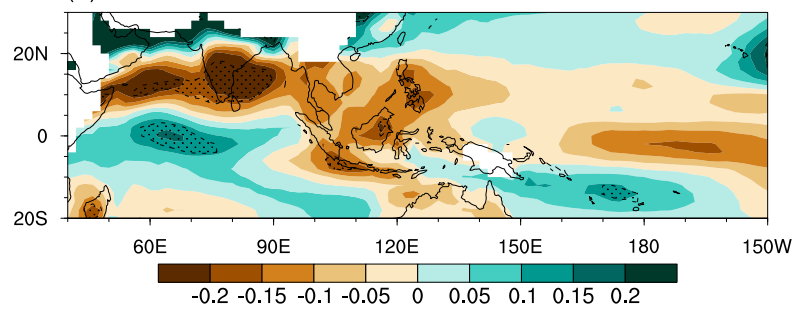

FIG. 11. The JJA mean low-level (925-700-hPa average) specific humidity fields (shading; $\mathrm{g} \mathrm{kg}^{-1}$ ) regressed onto the standardized WNPAC indices for (a) EP and (b) CP El Niño. Stippled regions indicate that the regressed mean specific humidity exceeds the $95 \%$ confidence level. 
(a) vorticity \& precipitation anomaly

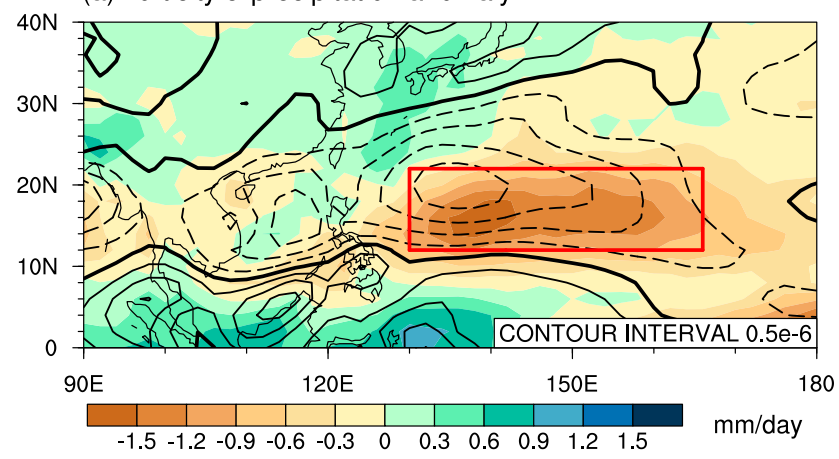

(c) convergence \& precipitation anomaly

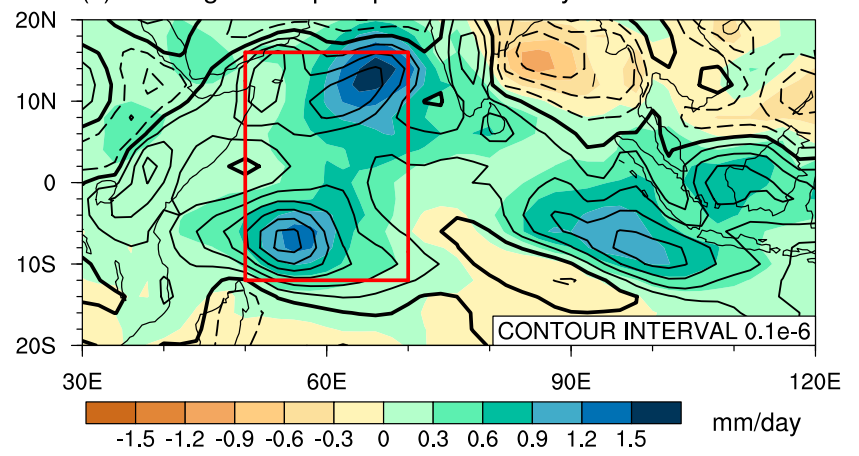

(b)

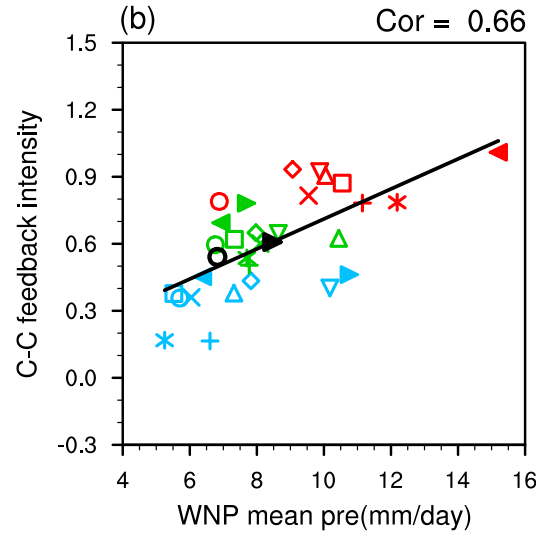

(d)

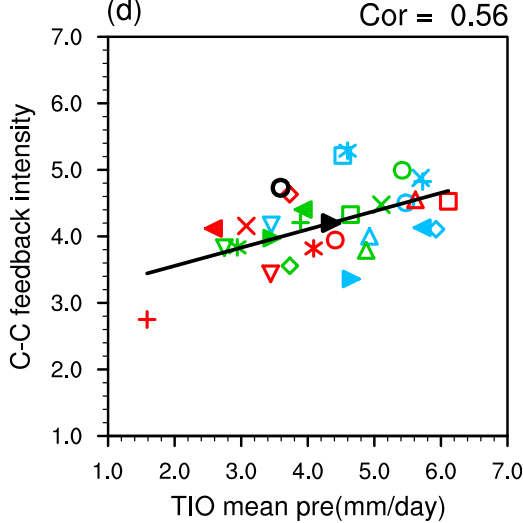

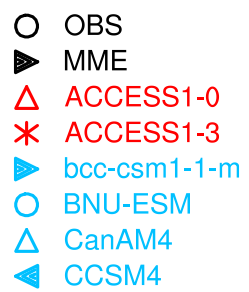

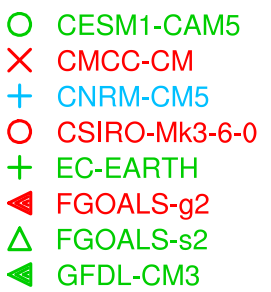

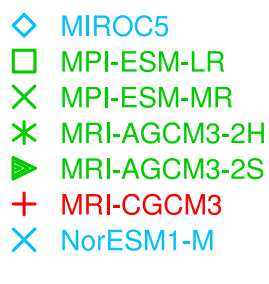

$\diamond$ MIROC5

$\square$ MPI-ESM-LR

X MPI-ESM-MR

* MRI-AGCM3-2H

$\checkmark$ MRI-AGCM3-2S

$\begin{array}{lll}* \text { IPSL-CM5A-LR } & + \text { MRI-CGCM3 } \\ \text { IPSL-CM5A-MR } & \times \text { NorESM1-M }\end{array}$

$\nabla$ IPSL-CM5B-LR

FIG. 12. (a) The MME of composite precipitation (shading; $\mathrm{mm} \mathrm{day}^{-1}$ ) and 1000-850-hPa-averaged relative vorticity (contours; $\mathrm{s}^{-1}$ ) anomalies during all El Niño decaying summers. The regression coefficient between anomalous precipitation and vorticity averaged over the red-outlined box for each model was used to measure the strength of the convection-circulation feedback. (b) Scatter diagram between the regression coefficient and JJA mean precipitation over the WNP. (c) As in (a), but for composite precipitation and 1000-850-hPa-averaged convergence anomalies. The regression coefficient between anomalous precipitation and convergence averaged over the red-outlined box for each model was used to measure the strength of the convection-circulation feedback. (d) Scatter diagram between the regression coefficient and JJA mean precipitation over the TIO. The correlation coefficients in both (b) and (d) exceed the $99 \%$ confidence level.

The physical mechanism behind the positive feedback is described as follows. A greater negative precipitation anomaly, on the one hand, induces a stronger low-level anticyclone anomaly to its west, as a Gill response to the anomalous heating. The enhanced northeasterly anomaly to the east of the anticyclone, on the other hand, strengthens the precipitation anomaly through the moist enthalpy advection mechanism (Wu et al. 2017a,b).

The relationship between the circulation-convection feedback intensity and the JJA mean precipitation over the WNP among all of the 29 models is revealed through a scatter diagram in Fig. 12b. Their correlation coefficient is 0.66 , which exceeds the $99 \%$ confidence level. It implies that a model with a stronger mean precipitation over the WNP favors a stronger local circulation-convection feedback and thus a stronger WNPAC in response to EP El Niño forcing.

As shown in Fig. 9b, the effect of the mean precipitation on the simulated WNPAC during CP El Niño is primarily through remote forcing from the TIO. To measure the local circulation-convection feedback over the equatorial IO, we first examine the MME of the precipitation and low-levelaveraged $(1000-850 \mathrm{hPa})$ divergence anomaly fields over the 
(a) WNP (selected models)

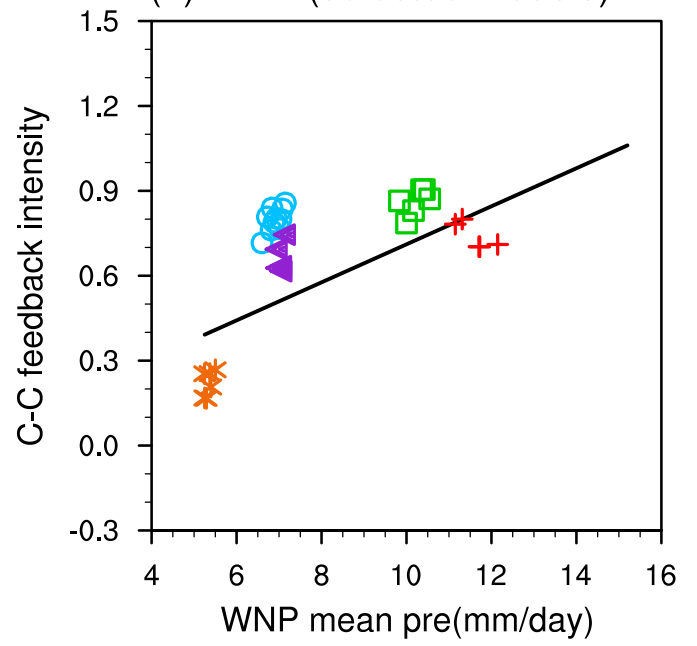

(b) TIO (selected models)

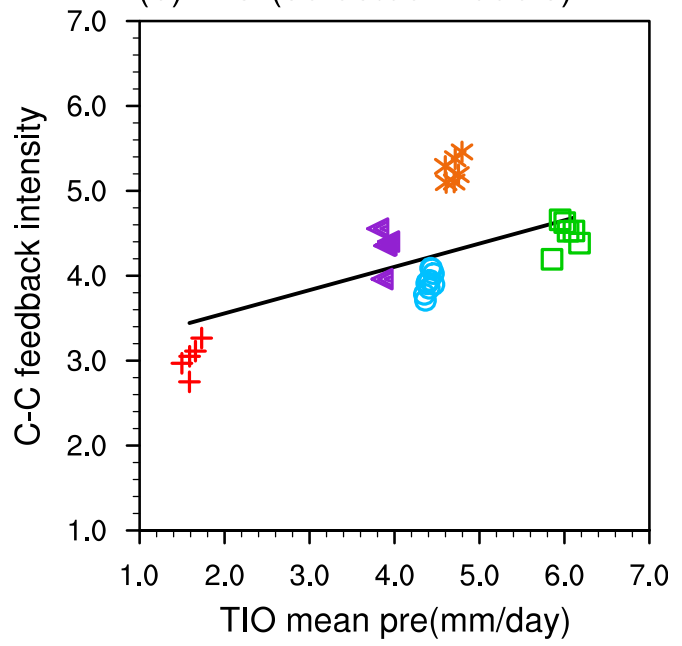

HadGEM2-A * IPSL-CM5A-LR

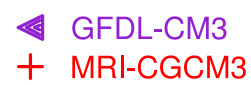

FIG. 13. As in Figs. 12b and 12d, but for multiple members of five selected models represented by different symbols. The black lines are the regression lines shown in Figs. 12b and 12d.

TIO. The reason to use the divergence instead of the vorticity is because the region of the interest is now near the equator. Note that there are positive precipitation and low-level convergence anomalies over the equatorial IO. Thus, a circulationconvection feedback index over the IO for each model is defined as the regression coefficient between the box-averaged $\left(12^{\circ} \mathrm{S}-16^{\circ} \mathrm{N}, 50^{\circ}-70^{\circ} \mathrm{E}\right.$; the red-outlined box in Fig. 12c) precipitation and low-level convergence anomalies for each summer from 1979 to 2008.

The mechanism for the positive circulation-convection feedback over the equatorial IO may be summarized as follows. A positive heating anomaly, on the one hand, induces anomalous low-level convergence and upper-level divergence. The so-induced ascending motion may further strengthen the heating through upward moisture transport.

The impact of the mean precipitation on the local circulation-convection feedback over the TIO is illustrated in Fig. 12d. A larger positive feedback intensity corresponds to a greater mean precipitation. The correlation coefficient between the feedback intensity and JJA mean precipitation over the TIO is 0.56 , exceeding the $99 \%$ confidence level. The result implies that greater mean precipitation and moisture over the TIO promote a greater local perturbation circulationconvection feedback, which could further induce a stronger WNPAC through the remote Kelvin wave forcing effect (Wu et al. 2009; Xie et al. 2009).

The five models with 5-10 members are also used to examine the magnitude of internal variability in the circulationconvection feedback. Figure 13 follows Figs. 12b and 12d. The result is similar to that derived from Fig. 10; that is, the internal variability is not large enough to overwhelm the model bias. Thus, the internal variability is not important in this regard and the intermodel difference of the circulationconvection feedback mainly arises from the model bias.
It is worth noting that the WNPAC-mean precipitation relationship in $\mathrm{CP}$ events is distinctive from EP events and the circulation-convection feedback strength over the WNP does not contribute to the intermodel difference of WNPAC during $\mathrm{CP}$ events. An explanation could be given as follows. A positive feedback can lead to the occurrence of either a cyclone or an anticyclone, depending on initial and persistent forcing processes. For CP events, the main driver is positive SSTA in the TIO, while the local WNP SSTA plays a passive role (i.e., local SSTA is a result of atmospheric forcing due to a negative precipitation anomaly, not the other way around). Thus, the intermodel difference of the WNPAC is mainly determined by the remote forcing from the TIO. This is in a great contrast to EP events in which the local cold SSTA in the WNP (Fig. 1b) is important.

\section{Conclusions and discussion}

By analyzing 29 AMIP experiments that were forced by the same prescribed SST field from 1979 to 2008, we evaluate the models' performance in capturing the WNPAC, an important circulation system in conveying the El Niño impact on East Asian climate. In this study we focus on examining the simulated WNPAC strength during the composite EP and CP El Niño decaying summers. A WNPAC intensity index is introduced to quantitatively measure the models' performance in capturing the WNPAC strength. It is defined as the negative sign of an areaaveraged $850-\mathrm{hPa}$ relative vorticity anomaly over the WNP. Most of the models are able to reproduce the observed pattern of the WNPAC in both EP and CP El Niños. The MME of the simulated WNPAC intensity is slightly weaker than the observed in both EP and CP El Niño cases. The models also capture the observed feature that the WNPAC associated with CP events is significantly weaker than that associated with EP events. 
EP

(a) Strong

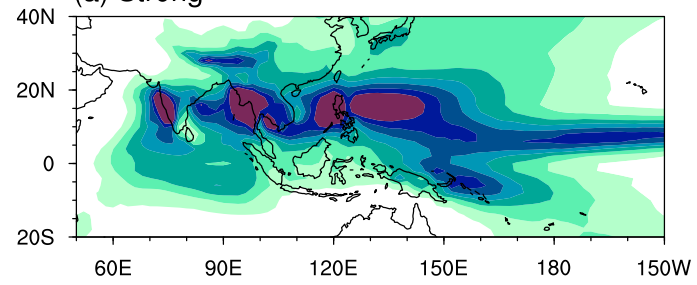

(b) Weak

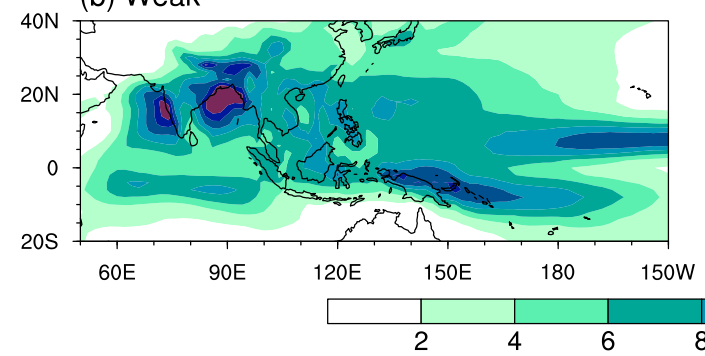

(d) Strong

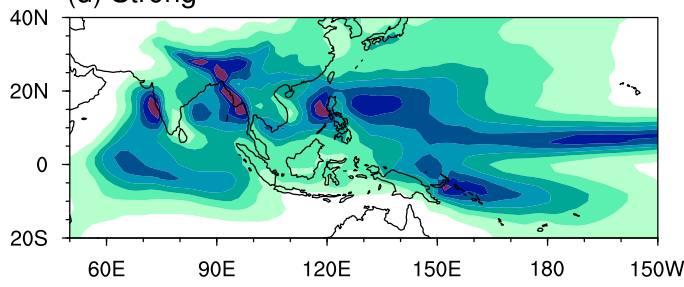

(e) Weak

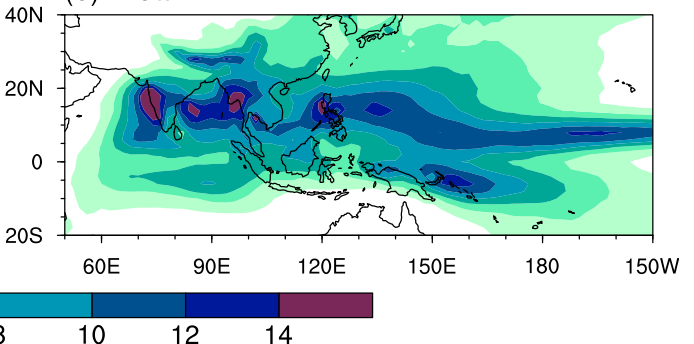

(f) difference

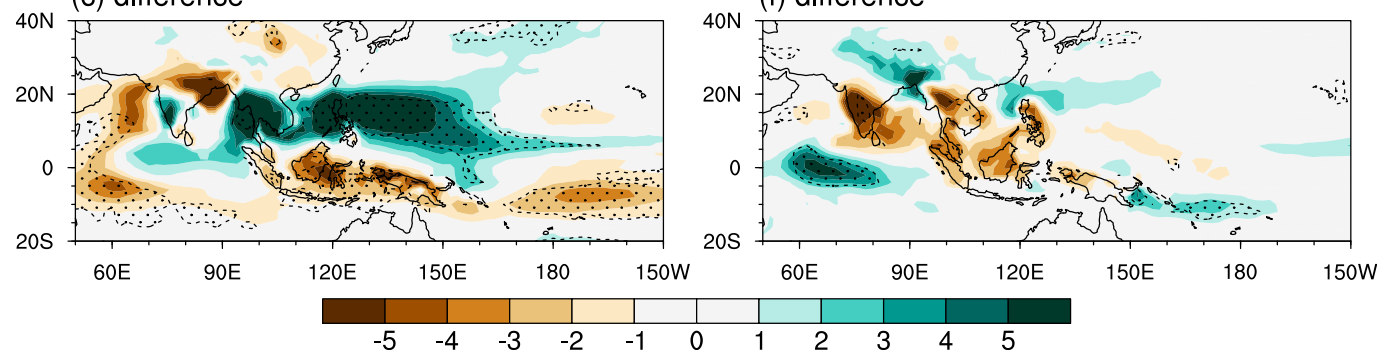

FIG. 14. Composite patterns of the JJA precipitation for models simulating (top) strong WNPAC (the strongest five), (middle) weak WNPAC (the weakest five), and (bottom) their difference, during (a)-(c) EP and (d)-(f) CP El Niño decaying summer.

A significant positive correlation is found between the simulated WNPAC intensity and JJA mean precipitation among the 29 models. This implies that a model that has a higher mean precipitation over the WNP simulates a stronger WNPAC during EP El Niño decaying summer. The physical mechanism behind the mean state-dependent characteristic is explained as follows. The models with higher mean precipitation also have a higher background moisture distribution because of their twoway interactive nature. On the one hand, a greater background mean precipitation favors a higher background mean moisture due to vertical moisture transport. On the other hand, a higher background mean moisture favors greater background mean precipitation because the same low-level wind convergence would lead to a greater mean moisture flux convergence. The higher mean precipitation and moisture further promote a greater perturbation circulation-convection feedback in situ, and thus a stronger WNPAC, even though all the models are forced by the same SSTA pattern.

The mean state dependence characteristic differs during CP El Niño cases. The intensity of the simulated WNPAC during CP El Niño decaying summer is associated with JJA mean precipitation over the TIO. This is because the remote IO forcing effect on the WNPAC becomes critical during CP El Niño decaying summer. A greater JJA mean precipitation over the TIO promotes a higher background moisture field in situ, which promotes a stronger local perturbation circulation-convection feedback. This, in turn, results in a stronger Kelvin wave response and thus a stronger WNPAC.

The distinctive WNPAC-mean precipitation relationships between the EP and CP El Niño result from different anomalous SST patterns in the WNP. A strong local negative SSTA appears during the EP El Niño decaying summer, but no significant negative SSTA signals are found over the WNP during CP El Niño composite. While the local SST anomaly plays an active role in maintaining the WNPAC during the EP events, it plays a passive role during the $\mathrm{CP}$ events. As a result, only the mean-state precipitation/moisture field in the tropical Indian Ocean modulates the circulation anomaly in the WNP in the latter case.

The influence of the magnitude of mean precipitation over particular regions on the simulations of WNPAC has been explained above. New questions arise: Are there precipitation pattern differences among the models, and are they also important to the simulations of WNPAC? We conduct a composite of mean precipitation for the models simulating strong 


\section{mean precipitation}

(a) EOF1

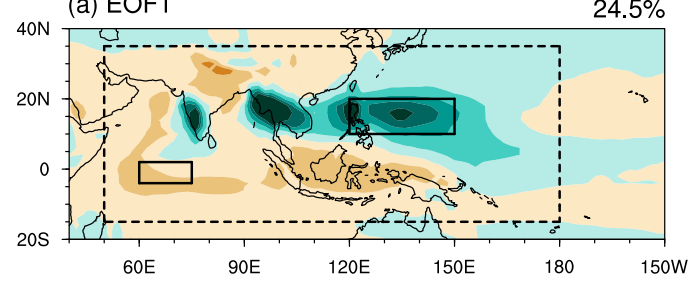

(c) EOF3

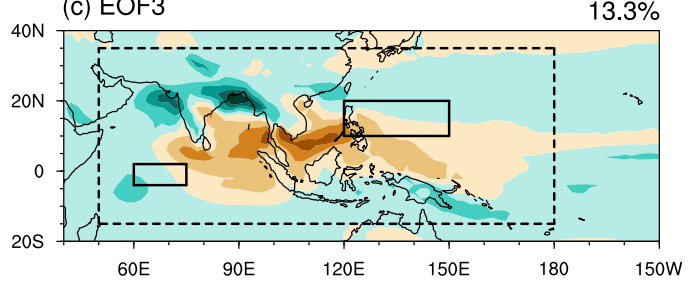

(b) EOF2

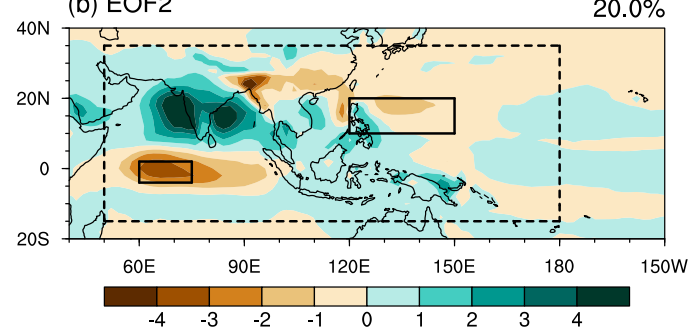

(d) MME

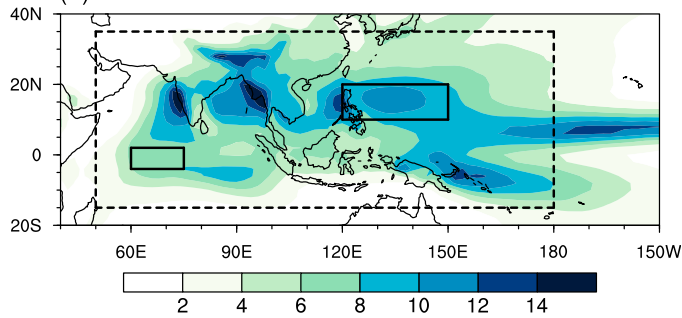

FIG. 15. The three leading intermodel EOF modes of JJA mean precipitation for all of the 29 models. The dashed outlines denote the area used for EOF analysis $\left(15^{\circ} \mathrm{S}-35^{\circ} \mathrm{N}, 50^{\circ}-180^{\circ} \mathrm{E}\right)$, and the solid outlines mark the regions used in Fig. 9.

versus weak WNPAC, and the result is shown in Fig. 14. It is seen that models with strong and weak WNPAC groups have a similar large-scale mean precipitation pattern in general for both the EP and CP cases. The most significant difference of the mean precipitation appears in the WNP and equatorial IO for the EP and CP cases, respectively. The composite difference patterns resemble Fig. 9 obtained based on a regression analysis. We also show the intermodel empirical orthogonal function (EOF) modes of JJA mean precipitation in Fig. 15, in which each model is treated as a sample. The EOF1 reflects the major difference of mean precipitation among these models. It is primarily located over the WNP and the Bay of Bengal (Fig. 15a). The maximum rainfall belt in this figure overlaps the main rain belt in the MME map (Fig. 15d). It indicates that the EOF1 mode is mainly associated with the magnitude of the mean precipitation. In the EOF2 mode, the most pronounced difference appears over the northern Indian Ocean. This EOF2 mode, to a large extent, is associated with the magnitude of the mean precipitation over the Indian Ocean. The EOF3 pattern seems to be associated with the north-south shifting of the mean rainfall pattern over the WNP. The analysis above indicates that the intermodel difference is primarily attributed to the magnitude of the mean precipitation field, while the pattern difference only accounts for a small portion of the intermodel difference.

It is worth mentioning that the number of El Niño events is limited because of limited length of the observational and model data. Thus, further work is needed to investigate whether the relationship between the simulated WNPAC strength and the JJA mean precipitation remains with a longer data period. Idealized numerical model experiments may be carried out to understand specific processes through which the mean state over the TIO and WNP modulates the WNPAC.
Acknowledgments. This work was jointly supported by NSFC Grant 42088101, NSF Grant AGS-20-06553, and Postgraduate Research and Practice Innovation Program of Jiangsu Province KYCX21_0943. This is SOEST contribution number 11411, IPRC contribution number 1539, and ESMC contribution number 356.

\section{REFERENCES}

Annamalai, H., B. Taguchi, J. P. McCreary, M. Nagura, and T. Miyama, 2017: Systematic errors in South Asian monsoon simulation: Importance of equatorial Indian Ocean processes. J. Climate, 30, 8159-8178, https://doi.org/10.1175/JCLI-D-16-0573.1.

Ashok, K., S. K. Behera, S. A. Rao, H. Y. Weng, and T. Yamagata, 2007: El Niño Modoki and its possible teleconnection. J. Geophys. Res., 112, C11007, https://doi.org/ 10.1029/2006JC003798.

Chang, C.-P., Y. S. Zhang, and T. Li, 2000a: Interannual and interdecadal variations of the East Asian summer monsoon and tropical Pacific SSTs. Part I: Roles of the subtropical ridge. J. Climate, 13, 4310-4325, https://doi.org/10.1175/15200442(2000)013<4310:IAIVOT>2.0.CO;2.

,-- , and $-2000 \mathrm{~b}$ : Interannual and interdecadal variations of the East Asian summer monsoon and tropical Pacific SSTs. Part II: Meridional structure of the monsoon. J. Climate, 13, 4326-4340, https://doi.org/10.1175/1520-0442(2000)013<4326: IAIVOT $>2.0 . \mathrm{CO} ; 2$.

Chen, M.-C., T. Li, X.-Y. Shen, and B. Wu, 2016: Relative roles of dynamic and thermodynamic processes in causing evolution asymmetry between El Niño and La Niña. J. Climate, 29, 22012220, https://doi.org/10.1175/JCLI-D-15-0547.1.

Chen, W., J.-K. Park, B. Dong, R. Lu, and W.-S. Jung, 2012: The relationship between El Niño and the western North Pacific summer climate in a coupled GCM: Role of the transition of El Niño decaying phases. J. Geophys. Res., 117, D12111, https://doi.org/10.1029/2011JD017385.

Dee, D. P., S. M. Uppala, and A. J. Simmons, 2011: The ERAInterim reanalysis: Configuration and performance of the data 
assimilation system. Quart. J. Roy. Meteor. Soc., 137, 553-597, https://doi.org/10.1002/qj.828.

Deser, C., I. R. Simpson, K. A. McKinnon, and A. S. Phillips, 2017: The Northern Hemisphere extratropical atmospheric circulation response to ENSO: How well do we know it and how do we evaluate models accordingly? J. Climate, 30, 5059-5082, https://doi.org/10.1175/JCLI-D-16-0844.1.

Fu, C., H. F. Diaz, and J. O. Fletcher, 1986: Characteristics of the response of sea surface temperature in the central Pacific associated with warm episodes of the Southern Oscillation. Mon. Wea. Rev., 114, 1716-1739, https://doi.org/10.1175/15200493(1986)114<1716:COTROS > 2.0.CO;2.

Gill, A. E., 1980: Some simple solutions for heat-induced tropical circulation. Quart. J. Roy. Meteor. Soc., 106, 447-462, https:// doi.org/10.1002/qj.49710644905.

Ham, Y.-G., J.-S. Kug, J.-Y. Park, and F.-F. Jin, 2013: Sea surface temperature in the north tropical Atlantic as a trigger for El Niño/Southern Oscillation events. Nat. Geosci., 6, 112-116, https://doi.org/10.1038/ngeo1686.

He, C., and T. Zhou, 2014: The two interannual variability modes of the western North Pacific subtropical high simulated by 28 CMIP5-AMIP models. Climate Dyn., 43, 2455-2469, https:// doi.org/10.1007/s00382-014-2068-x.

Hu, Z.-Z., A. Kumar, B. Jha, W. Wang, B. Huang, and B. Huang, 2012: An analysis of warm pool and cold tongue El Niños: Air-sea coupling processes, global influences, and recent trends. Climate Dyn., 38, 2017-2035, https://doi.org/10.1007/s00382-011-1224-9.

Jiang, L.-S., and T. Li, 2019: Relative roles of El Niño-induced extratropical and tropical forcing in generating tropical North Atlantic (TNA) SST anomaly. Climate Dyn., 53, 3791-3804, https://doi.org/10.1007/s00382-019-04748-7.

Jiang, W., G. Huang, P. Huang, R. Wu, K. Hu, and W. Chen, 2019: Northwest Pacific anticyclonic anomalies during post-El Niño summers determined by the pace of El Niño decay. J. Climate, 32, 3487-3503, https://doi.org/10.1175/JCLI-D-18-0793.1.

Kang, I. S., and Coauthors, 2002: Intercomparison of the climatological variations of Asian summer monsoon precipitation simulated by 10 GCMs. Climate Dyn., 19, 383-395, https:// doi.org/10.1007/s00382-002-0245-9.

Kug, J.-S., F.-F. Jin, and S.-I. An, 2009: Two types of El Niño events: Cold tongue El Niño and warm pool El Niño. J. Climate, 22, 1499-1515, https://doi.org/10.1175/2008JCLI2624.1.

Lau, K., J. H. Kim, and Y. Sud, 1996: Intercomparison of hydrologic processes in AMIP GCMs. Bull. Amer. Meteor. Soc., 77, 2209-2227, https://doi.org/10.1175/1520-0477(1996)077<2209: IOHPIA $>2.0 . \mathrm{CO} ; 2$.

Lau, N., and M. J. Nath, 2003: Atmosphere-ocean variations in the Indo-Pacific sector during ENSO episodes. J. Climate, 16, 3-20, https://doi.org/10.1175/1520-0442(2003)016<0003: AOVITI $>2.0 . \mathrm{CO} ; 2$.

Li, S., J. Lu, G. Huang, and K. Hu, 2008: Tropical Indian Ocean basin warming and East Asian summer monsoon: A multiple AGCM study. J. Climate, 21, 6080-6088, https://doi.org/ 10.1175/2008JCLI2433.1.

Li, T., and B. Wang, 2005: A review on the western North Pacific monsoon: Synoptic-to-interannual variabilities. Terr. Atmos. Oceanic Sci., 16, 285-314, https://doi.org/10.3319/ TAO.2005.16.2.285(A).

— , and P.-C. Hsu, 2017: Monsoon dynamics and its interactions with ocean. Fundamentals of Tropical Climate Dynamics, Springer, 236 pp., https://doi.org/10.1007/978-3-319-59597-9.

—, B. Wang, B. Wu, T. J. Zhou, C.-P. Chang, and R. H. Zhang, 2017: Theories on formation of an anomalous anticyclone in western North Pacific during El Niño: A review. J. Meteor. Res., 31, 987-1006, https://doi.org/10.1007/s13351-017-7147-6.

Nitta, T., 1987: Convective activities in the tropical western Pacific and their impact on the Northern Hemisphere summer circulation. J. Meteor. Soc. Japan, 65, 373-390, https://doi.org/ 10.2151/jmsj1965.65.3_373.

Rong, X. Y., R. H. Zhang, and T. Li, 2010: Impacts of Atlantic sea surface temperature anomalies on Indo-East Asian summer monsoon-ENSO relationship. Chin. Sci. Bull., 55, 2458-2468, https://doi.org/10.1007/s11434-010-3098-3.

Shi, J., and W. Qian, 2018: Asymmetry of two types of ENSO in the transition between the East Asian winter monsoon and the ensuing summer monsoon. Climate Dyn., 51, 3907-3926, https://doi.org/10.1007/s00382-018-4119-1.

Tao, W., G. Huang, K. Hu, H. Gong, G. Wen, and L. Liu, 2015: A study of biases in simulation of the Indian Ocean basin mode and its capacitor effect in CMIP3/CMIP5 models. Climate Dyn., 46, 205-226, https://doi.org/10.1007/s00382-015-2579-0.

,,-- R. Wu, K. Hu, P. Wang, and H. Gong, 2018: Origins of biases in CMIP5 models simulating northwest Pacific summertime atmospheric circulation anomalies during the decaying phase of ENSO. J. Climate, 31, 5707-5729, https:// doi.org/10.1175/JCLI-D-17-0289.1.

,,-- P. Wang, Y. Liu, G. Wen, and D. Dong, 2019: Dominant modes of CMIP3/5 models simulating northwest Pacific circulation anomalies during post-ENSO summer and their SST dependence. Theor. Appl. Climatol., 138, 1809-1820, https:// doi.org/10.1007/s00704-019-02936-3.

Taylor, K. E., R. J. Stouffer, and G. A. Meehl, 2012: An overview of CMIP5 and the experiment design. Bull. Amer. Meteor. Soc., 93, 485-498, https://doi.org/10.1175/BAMS-D-11-00094.1.

Trenberth, K. E., and D. P. Stepaniak, 2001: Indices of El Niño evolution. J. Climate, 14, 1697-1701, https://doi.org/10.1175/ 1520-0442(2001)014<1697:LIOENO>2.0.CO;2.

Wang, B., and Q. Zhang, 2002: Pacific-East Asian teleconnection. Part II: How the Philippine Sea anomalous anticyclone is established during El Niño development. J. Climate, 15, 3252-3265, https://doi.org/10.1175/1520-0442(2002)015<3252: PEATPI $>2.0 . \mathrm{CO} ; 2$.

connection: How does ENSO affect East Asian climate? J. Climate, 13, 1517-1536, https://doi.org/10.1175/15200442(2000)013<1517:PEATHD>2.0.CO;2.

,$- \ldots$, and T. Li, 2003: Atmosphere-warm ocean interaction and its impacts on Asian-Australian monsoon variation. J. Climate, 16, 1195-1211, https://doi.org/10.1175/1520-0442(2003) 16<1195:AOIAII >2.0.CO;2.

_- B. Xiang, and J.-Y. Lee, 2013: Subtropical high predictability establishes a promising way for monsoon and tropical storm predictions. Proc. Natl. Acad. Sci. USA, 110, 2718-2722, https://doi.org/10.1073/pnas.1214626110.

Wu, B., T. Zhou, and T. Li, 2009: Seasonally evolving dominant interannual variability modes of East Asian climate. J. Climate, 22, 2992-3005, https://doi.org/10.1175/2008JCLI2710.1.

— T. Li, and T. Zhou, 2010: Relative contributions of the Indian Ocean and local SST anomalies to the maintenance of the western North Pacific anomalous anticyclone during the El Niño decaying summer. J. Climate, 23, 2974-2986, https:// doi.org/10.1175/2010JCLI3300.1.

_ namic processes driving the western North Pacific anomalous anticyclone during El Niño. Part I: Maintenance mechanisms. J. Climate, 30, 9621-9635, https://doi.org/10.1175/JCLI-D-16-0489.1. 
$[,-$, and 2017b: Atmospheric dynamic and thermodynamic processes driving the western North Pacific anomalous anticyclone during El Niño. Part II: Formation processes. J. Climate, 30, 9637-9650, https://doi.org/10.1175/JCLI-D-160495.1.

Wu, R. G., Z. Z. Hu, and B. P. Kirtman, 2003: Evolution of ENSO-related rainfall anomalies in East Asia. J. Climate, 16, 3742-3758, https://doi.org/10.1175/1520-0442(2003)016<3742: EOERAI $>2.0 . \mathrm{CO} ; 2$.

Xie, P. P., and P. A. Arkin, 1997: Global precipitation: A 17-year monthly analysis based on gauge observations, satellite estimates, and numerical model outputs. Bull. Amer. Meteor. Soc., 78, 2539-2558, https://doi.org/10.1175/1520-0477(1997)078<2539: GPAYMA $>2.0 . \mathrm{CO} ; 2$.

Xie, S.-P., K. Hu, J. Hafner, H. Tokinaga, Y. Du, G. Huang, and T. Sampe, 2009: Indian Ocean capacitor effect on Indo-western Pacific climate during the summer following El Niño. J. Climate, 22, 730-747, https://doi.org/10.1175/2008JCLI2544.1.

, Y. Kosaka, Y. Du, K. Hu, J. S. Chowdary, and G. Huang, 2016: Indo-western Pacific Ocean capacitor and coherent climate anomalies in post-ENSO summer: A review. $A d v$. Atmos. Sci., 33, 411-432, https://doi.org/10.1007/s00376-0155192-6.
Yang, J. L., Q. Y. Liu, S. P. Xie, Z. Y. Liu, and L. X. Wu, 2007: Impact of the Indian Ocean SST basin mode on the Asian summer monsoon. Geophys. Res. Lett., 34, L02708, https:// doi.org/10.1029/2006GL028571.

Yu, J. H., T. Li, Z. Tan, and Z. Zhu, 2016: Effects of tropical North Atlantic SST on tropical cyclone genesis in the western North Pacific. Climate Dyn., 46, 865-877, https://doi.org/10.1007/ s00382-015-2618-x.

Yu, J. Y., Y. Zou, S.-T. Kim, and T. Lee, 2012: The changing impact of El Niño on US winter temperatures. Geophys. Res. Lett., 39, L15702, https://doi.org/10.1029/2012GL052483.

Zhang, R. H., A. Sumi, and M. Kimoto, 1996: Impact of El Niño on the East Asian monsoon: A diagnostic study of the '86/87 and '91/92 events. J. Meteor. Soc. Japan, 74, 49-62, https://doi.org/ 10.2151/jmsj1965.74.1_49.

—, Q. Min, and J. Z. Su, 2017: Impact of El Niño on atmospheric circulations over East Asia and rainfall in China: Role of the anomalous western North Pacific anticyclone. Sci. China Earth Sci., 60, 1124-1132, https://doi.org/10.1007/s11430-016-9026-x.

Zhang, W., F.-F. Jin, J. X. Zhao, L. Qi, and H.-L. Ren, 2013: The possible influence of a nonconventional El Niño on the severe autumn drought of 2009 in southwest China. J. Climate, 26, 8392-8405, https://doi.org/10.1175/JCLI-D-12-00851.1. 
